\title{
A single transcription factor is sufficient to induce and maintain secretory cell architecture
}

\author{
Hei-Yong G. Lo, ${ }^{1}$ Ramon U. Jin, ${ }^{1}$ Greg Sibbel, ${ }^{1}$ Dengqun Liu, ${ }^{2}$ Anju Karki, ${ }^{3,4}$ Matthew S. Joens, ${ }^{5}$ \\ Blair B. Madison, ${ }^{1}$ Bo Zhang, ${ }^{6}$ Valerie Blanc, ${ }^{1}$ James A.J. Fitzpatrick, ${ }^{5}$ Nicholas O. Davidson, ${ }^{1,6}$ \\ Stephen F. Konieczny, ${ }^{3,4}$ and Jason C. Mills ${ }^{1,6,7}$ \\ ${ }^{1}$ Division of Gastroenterology, Department of Medicine, Washington University School of Medicine, St. Louis, Missouri 63110, \\ USA $^{2}$ Institute of Combined Injury, State Key Laboratory of Trauma, Burns and Combined Injury, College of Preventive Medicine, \\ Third Military Medical University, Chongqing 400038, China; ${ }^{3}$ Department of Biological Sciences, The Purdue Center for Cancer \\ Research, ${ }^{4}$ the Bindley Bioscience Center, Purdue University, West Lafayette, Indiana 47906, USA; ${ }^{5}$ Washington University Center \\ for Cellular Imaging, ${ }^{6}$ Department of Developmental Biology, ${ }^{7}$ Department of Pathology and Immunology, Washington University \\ School of Medicine, St. Louis, Missouri 63110, USA
}

We hypothesized that basic helix-loop-helix (bHLH) MIST1 (BHLHA15) is a "scaling factor" that universally establishes secretory morphology in cells that perform regulated secretion. Here, we show that targeted deletion of MIST1 caused dismantling of the secretory apparatus of diverse exocrine cells. Parietal cells (PCs), whose function is to pump acid into the stomach, normally lack MIST1 and do not perform regulated secretion. Forced expression of MIST1 in PCs caused them to expand their apical cytoplasm, rearrange mitochondrial/lysosome trafficking, and generate large secretory granules. Mist1 induced a cohort of genes regulated by MIST1 in multiple organs but did not affect PC function. MIST1 bound CATATG/CAGCTG $E$ boxes in the first intron of genes that regulate autophagosome/lysosomal degradation, mitochondrial trafficking, and amino acid metabolism. Similar alterations in cell architecture and gene expression were also caused by ectopically inducing MIST1 in vivo in hepatocytes. Thus, MIST1 is a scaling factor necessary and sufficient by itself to induce and maintain secretory cell architecture. Our results indicate that, whereas mature cell types in each organ may have unique developmental origins, cells performing similar physiological functions throughout the body share similar transcription factor-mediated architectural "blueprints."

[Keywords: acid secretion; 5330417C22Rik; RAB26; UFM1; FIB-SEM]

Supplemental material is available for this article.

Received June 16, 2016; revised version accepted January 13, 2017.

Multicellularity evolved as organisms acquired the capacity to differentiate the function of one cell from the functions of other cells. Such cellular differentiation depends on cell-specific transcription factors that regulate expression of distinct cohorts of genes to establish cellular identity (Degnan et al. 2009). In the body of a mammal, there are hundreds of specific cell lineages distributed throughout dozens of different organs. Each of the hundreds of cell types in an adult organism has its own unique, developmentally regulated sequence of cell fate-determining transcription factors that direct the cell lineage's path to its mature identity. The sequence of transcription factors governing such cell fate/identity choices for each cell type is rapidly being determined. For example, the transcription factor sequence that instructs the progeny of

Corresponding author: jmills@wustl.edu

Article published online ahead of print. Article and publication date are online at http://www.genesdev.org/cgi/doi/10.1101/gad.285684.116. an embryonic stem cell to eventually become an insulin-secreting $\beta$ cell in the pancreas has been largely elucidated (D'Amour et al. 2006), and the sequence of cell fatedeciding transcription factors necessary to direct the differentiation of the principal cell lineages for most other organs is similarly being uncovered (Hu et al. 2010; Ieda et al. 2010; Spence et al. 2011; Takayama et al. 2012; Morris et al. 2014).

Although there are hundreds of cell types and cell-specific transcription factor sequences governing their differentiation, the actual functions of terminally differentiated cells are far less diverse. To illustrate: Exocrine cells that secrete digestive enzymes in the salivary glands, pancreas,

(C) 2017 Lo et al. This article is distributed exclusively by Cold Spring Harbor Laboratory Press for the first six months after the full-issue publication date (see http://genesdev.cshlp.org/site/misc/terms.xhtml). After six months, it is available under a Creative Commons License (Attribution-NonCommercial 4.0 International), as described at http://creativecommons.org/licenses/by-nc/4.0/. 
and stomach have unique developmental derivations and secrete organ-specific digestive enzymes. However, their secretory apparatus and, indeed, their overall subcellular organization are similar. Based in part on these observations, we propose that there are transcription factors that are expressed as part of the developmental/differentiation program of a cell, but, unlike cell fate-directing transcription factors, these factors govern only how a cell organizes its subcellular machinery to perform a specific function (Mills and Taghert 2012). Specifically, such transcription factors would have the function of scaling up the specific aspects of cellular structure/function that are needed for a cell to be particularly efficient at a specific task. For example, cells that secrete proteins in a regulated fashion all tend to have expansive apical cytoplasms with basal nuclei and large secretory granules. From an evolutionary standpoint, it would be economical if the same transcription factor could govern these structural changes in the diverse cells that perform the secretory function even if the cells arise via distinct differentiation sequences in multiple tissues.

The transcription factor basic helix-loop-helix (bHLH) MIST1 (BHLHA15) is a prototype for such a secretory architecture "scaling factor." It is expressed in cells of diverse developmental origins whose only commonality is long-lived, large-scale secretion of protein (Pin et al. 2000, 2001; Zhao et al. 2006; Capoccia et al. 2011; Chikada et al. 2015). MIST1 is developmentally regulated in that it is expressed during terminal differentiation of such cells. However, it does not determine cell identity, instead governing only genes that elaborate secretory cell architecture and not the cell lineage-specific cargo that a cell secretes (Mills and Taghert 2012). DIMM, the MIST1 ortholog in Drosophila, functions in an analogous way: simply to regulate secretory architecture, not cell fate (Hamanaka et al. 2010; Park et al. 2011).

MIST1 expression is directly activated by X-box-binding protein 1 (XBP1), which also serves to elaborate the abundant, lamellar rough ER network that is necessary to generate the massive loads of protein cargo to be packaged into the large, MIST1-mediated secretory granules (Huh et al. 2010). The XBP1 $\rightarrow$ MIST1 cassette is required in secretory cells of diverse tissues to establish the cargogenerating, packaging, and secreting machinery for professional secretory cells (Metzler et al. 2015). The epithelium of the body of the stomach is a good model for studying cell fate-determining transcription factors versus scaling factors because it is organized into roughly tubular invaginations (units) with distinct zones of cell types and a stem cell that actively generates all of the cell types throughout life (Mills and Shivdasani 2011; Willet and Mills 2016). The two key long-lived cell types in the gastric unit are the acid-pumping parietal cells (PCs) and the digestive enzyme-secreting zymogenic chief cells (ZCs). PCs emerge from stem cells through a brief transition (Karam 1993), whereas ZCs have a long precursor stage (the mucous neck cell), during which the precursors migrate toward the base of the gastric unit (away from the stomach lumen) (Karam and Leblond 1993; Ramsey et al. 2007). As they enter the base, they undergo sudden XBP1 $\rightarrow$
MIST1-mediated transition into secretory factories with enormous rER networks that produce and package cargo-like Pepsinogen II (PGII) and, in rodents, gastric intrinsic factor (GIF) into densely packed, large secretory granules (Shao et al. 1998; Huh et al. 2010).

Previous studies have shown that constitutive absence of MIST1 (in Mist1 $1^{-/-}$mice) leads to ZCs with smaller, less abundant granules with loss of normal basal localization of the nucleus (Pin et al. 2001; Johnson et al. 2004; Ramsey et al. 2007; Direnzo et al. 2012). To date, MIST1 has not been removed from cells that had already matured in its presence and has not been ectopically expressed in cells that normally do not express MIST1. Both of these experiments are critical to support the hypothesis that MIST1 acts as a scaling factor because it is critical to demonstrate that (1) decrease of MIST1 will scale the secretory apparatus down again, showing that MIST1 is directly responsible for maintaining secretory architecture; (2) MIST1 by itself is sufficient to scale up secretory architecture; and (3) MIST1 expression in cells of different cell lineages will result in the same subcellular phenotype.

Here, we performed those key experiments: We induced loss of MIST1 from MIST1-expressing secretory cells and ectopically expressed MIST1 in PCs, which normally lack MIST1. We show that MIST1 regulates a cohort of transcriptional targets that is tissue-independent and that MIST1 uses those targets to directly govern elaboration of secretory cell machinery without affecting cell identity or fate. Thus, a single transcription factor is necessary and sufficient for scaling secretory cell architecture in diverse cell types.

\section{Results}

Continuous Mist1 expression is required to maintain secretory cell architecture

During cellular differentiation of dedicated exocrine secretory cells, MIST1 abundance increases, causing a scaling up of secretory granule number and size as well as changes in orientation of subcellular compartments to accommodate the large stores of apical granules. This role of MIST1 is well established, but we hypothesized recently that, during times of stress, a cell could also scale its secretory function down simply by decreasing the abundance (downscaling) of MIST1 (Mills and Taghert 2012), thereby acting as a cellular rheostat for the energy-intensive cellular process of secretion.

To test the hypothesis that loss of MIST1 from cells actively expressing abundant MIST1 leads to decreased secretory architecture, we generated Mist $1^{\text {CreERT2/flox }}$ mice. Treating these mice with tamoxifen causes the tamoxifen-responsive Cre recombinase knocked into one Mist1 allele to delete the other, floxed allele, thereafter rendering Mist1-expressing cells null for MIST1. We used this low-dose tamoxifen administration to avoid gastric toxicity and delete Mist1 from 6- to 8-wk-old adult Mist $1^{\text {CreERT2/flox }}$ mice (see the Materials and Methods). By 2 wk after the initial tamoxifen dose, as expected, ZCs expressing MIST1 were rare (note the loss of myc- 
tagged MIST1) (Fig. 1A; Supplemental Fig. S1A). In low-dose tamoxifen-treated stomachs, consistent with our working hypothesis that MIST1 functions as a scaling factor only for secretory cell architecture, loss of Mist1 did not cause cell death, loss of cell identity, or a change in the type of cargo within secretory granules. Figure 1, A and B, shows that the ZCs in the absence of MIST1 still inhabit their distinct zone at the base of the gastric unit and express GIF, one of the principal secreted proteins in murine ZCs.

In contrast, the ZCs deprived of MIST1 showed multiple abnormalities in secretory cell architecture. Mis$t 1^{\mathrm{CreERT} / \Delta} \mathrm{ZCs}$ were $26 \% \pm 3 \%$ smaller on average $(P<$ $0.001)$, resulting in larger gastric unit lumens in the base region of the gastric unit (see in particular Fig. 1B, where a region with markedly smaller cells is depicted), which has been reported as a phenotype of Mist $1^{-/-}$exocrine cells (Bredemeyer et al. 2009; Direnzo et al. 2012). The most common abnormality shown previously in multiple cell lineages by multiple investigators upon loss of MIST1 is the loss of an expansive apical compartment containing abundant, large secretory granules (Pin et al. 2001; Ramsey et al. 2007; Capoccia et al. 2013). To quantify this cellular architectural feature in our mice, we measured $\sim 1000$ secretory granules in Mist $1^{\text {CreERT2/s }}$ and control ZCs using confocal microscopy, which revealed a highly significant decrease in granule size in ZCs that have lost MIST1 (Fig. 1C). To determine the extent of loss of the apical compartment (the portion of the cell between the nucleus and the lumen), we quantified nuclear eccentricity (i.e., how far the nucleus was from the luminal or basal plasma membrane). In control cells, nuclei were almost always within the basal quarter of the cell (Fig. 1A-C), indicating an expansive apical compartment for secretory granules. In contrast, loss of MIST1 caused a statistically significant relocalization of the nucleus away from the base, thereby defining a reduced apical cell compartment (Fig. 1A-C). In most cells deprived of MIST1, the majority
A
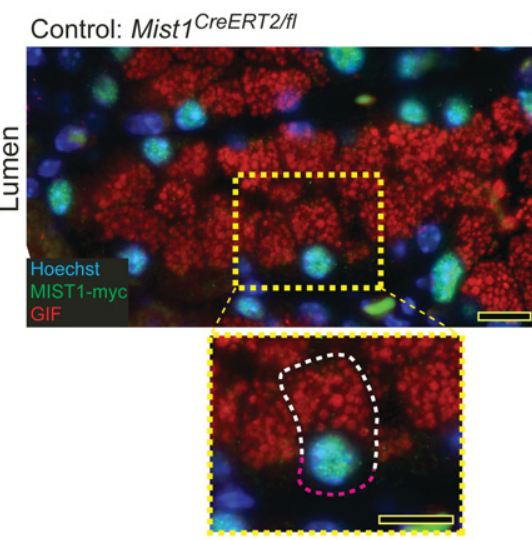

B
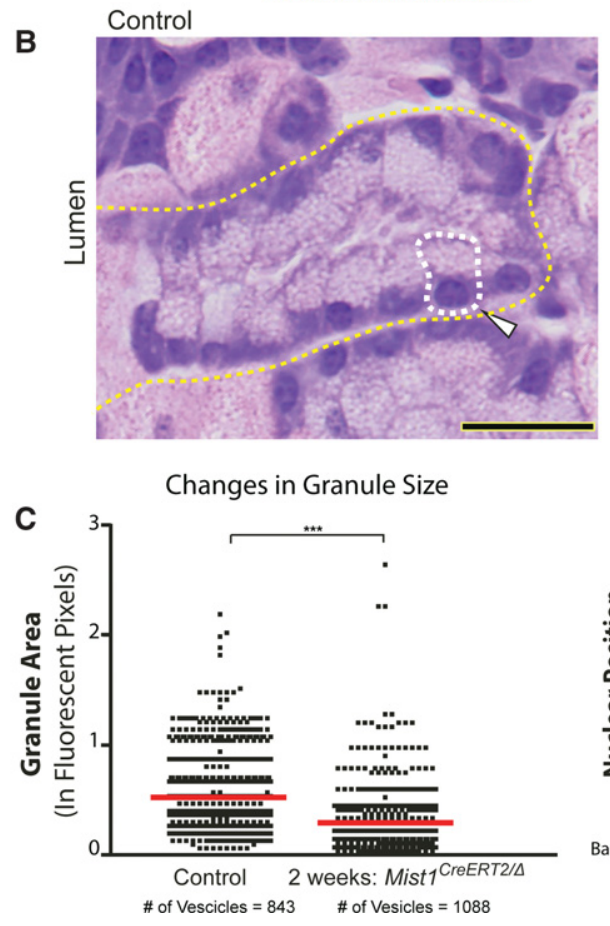

2 weeks: Mist 1 CreERT2/A
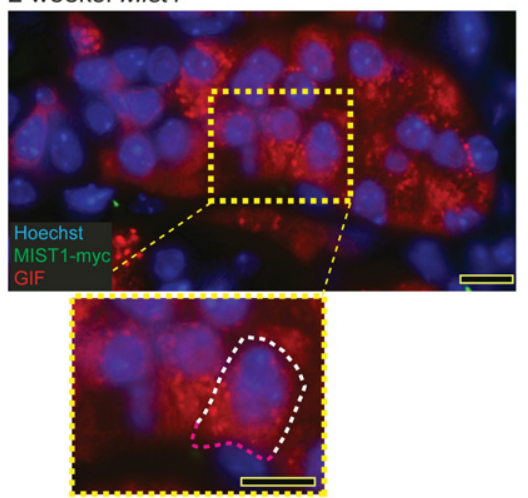

2 weeks: Mist 1 CreERT2/ $\Delta$

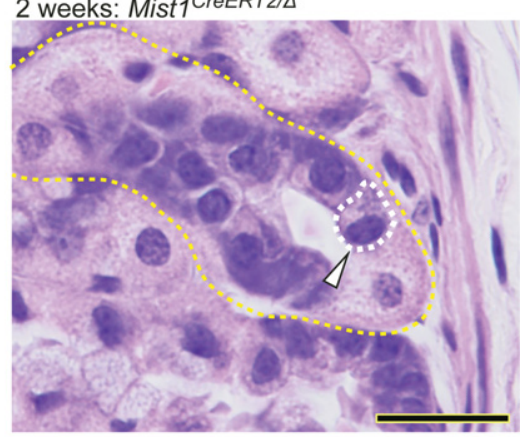

Change in Nuclear Position

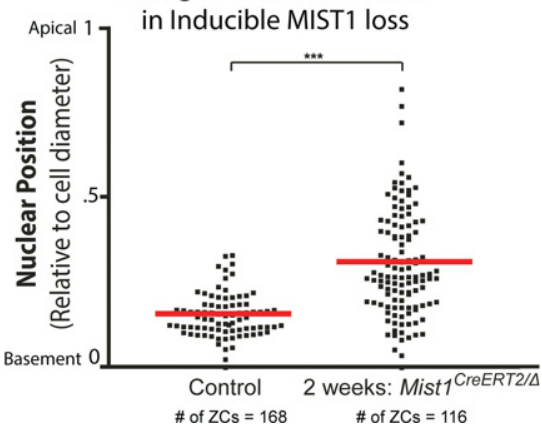

Figure 1. MIST1 is required for maintenance of secretory cell architecture in the stomach. (A) Epifluorescent images of the basal ZC-rich portion of gastric units following induced deletion of MIST1 ([green] antibody vs. myc tag on MIST1) in ZCs 2 wk after the first tamoxifen injection. ZCs lacking MIST1 exhibit smaller, disorganized GIF granules (red) with nuclear repositioning from the cell base (pink dashed outline) to the cell apex (white dashed outline). (B) Representative H\&E images of the base of the gastric unit (yellow dashed outline), showing ZCs (white dashed outline) in response to deletion of MIST1. Arrowheads indicate nuclei with changed positions relative to the apical-basal axis. $(C)$ Quantification of confocal images shows reduced cell granule size $(n=2$ mice; $P<$ 0.001 ) and nucleus migration $97 \% \pm 12 \%$ toward the center of the cell as MIST1 is lost. $P<0.001$. A one-tailed Student's $t$-test was used to determine statistical significance. Bars: $A, 10 \mu \mathrm{m} ; B, 20 \mu \mathrm{m}$. 
of secretory granules was mislocalized basal to the nucleus instead of apical (e.g., see Fig. 1A).

MIST1 is expressed in a relatively limited cohort of cells that all have in common long life spans and large-scale secretion of protein. To confirm that other MIST1-positive cells required continued expression of MIST1 to maintain their specialized secretory apparatus, we studied the effects of induced deletion of Mist1 in two different salivary glands as well as the pancreas. All showed mislocalization of the nucleus within 2 wk of loss of MIST1 (Fig. 2A,B), and MIST1-ablated salivary gland cells decreased in size: submandibular by $32 \% \pm 2 \%(P<0.001)$ and parotid by $17 \% \pm 3 \%(P<0.001)$. Pancreatic acinar cells are known to be smaller in the perpetual absence of MIST1 (Direnzo et al. 2012) but did not show statistically significant shrinkage within $2 \mathrm{wk}$ in the mice examined.

Thus, MIST1 is not necessary for cell survival or identity but must be actively and continuously expressed at abundant levels to maintain secretory cell architecture in cells of diverse embryonic origin.
Forced ectopic expression of MIST1 in a nonexocrine secretory cell does not change cell identity

Next, we wanted to test the hypothesis that MIST1 alone is sufficient to scale up the specialized secretory apparatus without altering cell identity. In other words, we wanted to determine whether MIST1 could establish specialized secretory cell architecture without inducing expression of any specific cargo to be secreted by that apparatus. We selected a cell that does not normally express MIST1 but is a neighbor of the $\mathrm{ZC}$ within the gastric unit. We reasoned that the fact that the two cell types occupy neighboring niches would minimize potential confounding influences of different extracellular milieus. Acid-producing PCs use $\mathrm{H}^{+}-\mathrm{K}^{+}$-ATPase to pump hydrogen ions into the lumen but do not have secretory granules or regulated secretion and, accordingly, do not express MIST1 (Bredemeyer et al. 2009; Lennerz et al. 2010). Additionally, we previously developed and characterized a mouse line that contains a randomly inserted Cre recombinase

\section{A Nuclear Position in response to loss of MIST1}

(Relative to cell diameter)

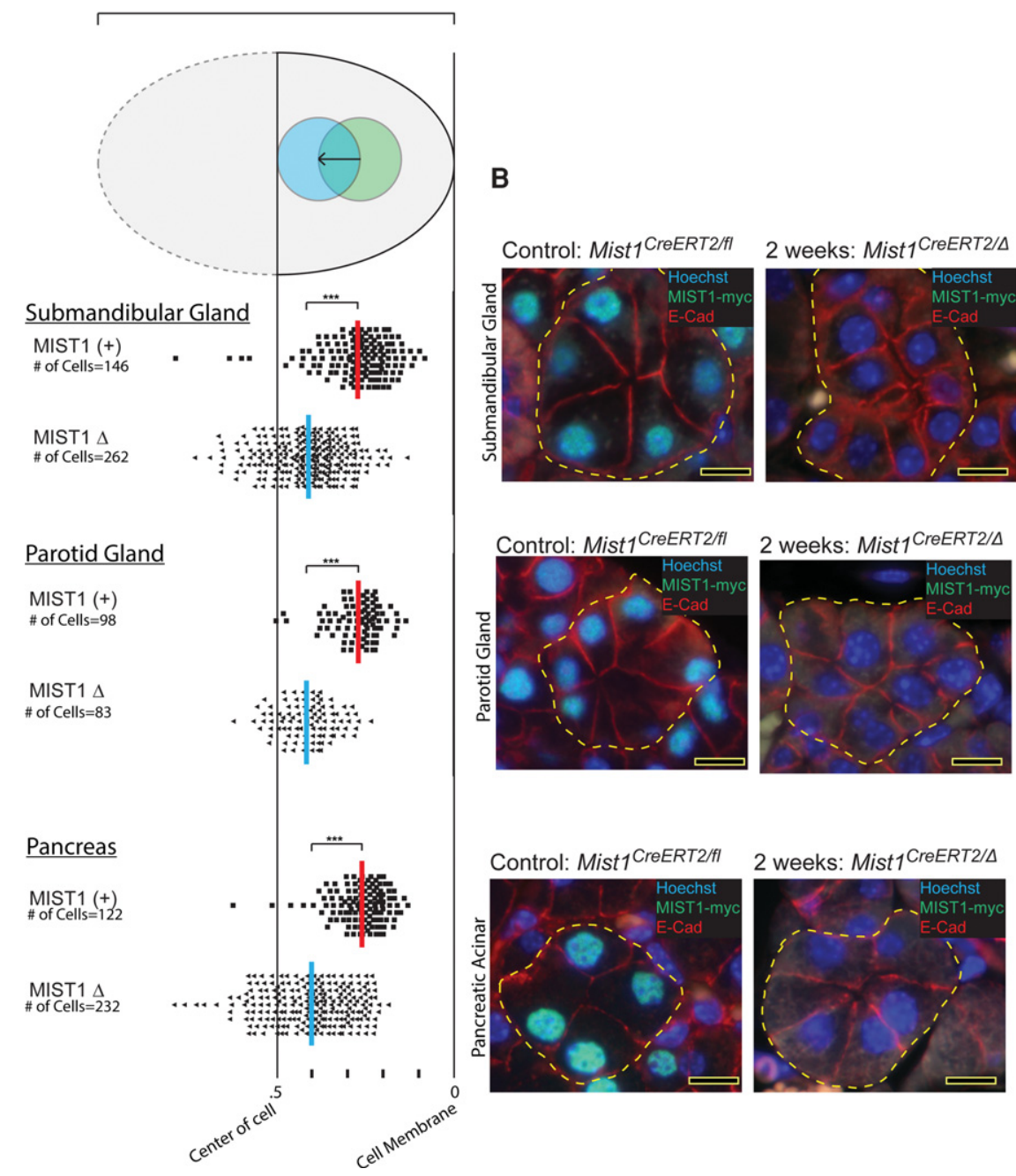

Figure 2. MIST1 is required for maintenance of secretory cell architecture in other organs. (A) Quantification of nuclear position in acinar cells from two different salivary glands and the pancreas. Loss of MIST1 caused the nuclei to move $53 \% \pm$ $4 \%, 53 \% \pm 4 \%$, and $56 \% \pm 5 \%$ closer to the center in the submandibular, parotid, and pancreatic acinar cells, respectively. (B) Epifluorescent images of acinar cells from the specified organ highlighting apical-basal organization with respect to the nucleus (blue) and cell basolateral cell boundaries (E-cadherin; red) in $\mathrm{MIST1}^{+}$ (green) and MIST1-deleted (" $\Delta^{\prime \prime}$ ) cells. Bar, $10 \mu \mathrm{m}$. 
transgene under the control of the $\beta$ subunit of the $\mathrm{H}^{+}-\mathrm{K}^{+}$ATPase gene $(A t p 4 b)$ promoter. Cre expression is highly specific to stomach and, within the stomach, is expressed only in PCs and their immediate progenitors (Syder et al. 2004; Huh et al. 2012).

We generated Atp $4 b$-Cre; LSL-Mist $1^{\text {myc }}$ mice and analyzed them relative to Atp $4 b$-Cre controls. Ectopic expression of MIST1 occurred in nearly all PCs, which was verified through immunofluorescence for myc-tagged exogenous MIST1 as well as MIST1 itself (Fig. 3A). MIST1 induction in PCs did not block PC lineage-specific makers; mutant PCs (referred to here as "MIST1-PCs") maintained characteristic markers, such as prominent ezrin networks (Fig. 3A; Supplemental Fig. S1B; Schubert 2009; Zhu et al. 2010) and $\mathrm{H}^{+}-\mathrm{K}^{+}$-ATPase (Supplemental Fig. S2A). MIST1 expression in PCs likewise did not induce expression of cargo proteins, such as GIF and PGC (pepsinogen C), normally secreted by ZCs (Supplemental Figs. S1B, S2B). Furthermore, overexpression of MIST1 did not detectably alter PC function: There was no differ- ence in expression of the acid-sensitive gene Gastrin in the stomach (Supplemental Fig. S1C), and, accordingly, gastric $\mathrm{pH}$ was indistinguishable between mutant and control mice (Supplemental Fig. S1C). MIST1-PCs were slightly $(12 \% \pm 3 \%)$ smaller in the area measured from tissue sections $(P<0.05)$, but there was no significant difference in the number of PCs per gastric unit in the mutant mice (Supplemental Fig. S2C,D).

\section{Ectopic expression of MIST1 is sufficient to completely remodel PC architecture}

We next sought to test the key hypothesis that initiated our studies: Is a single transcription factor, ectopically expressed in a mature cell lineage, sufficient by itself to reprogram the cellular architecture of a cell that normally does not express it? PCs are large, roughly trapezoidal cells. They have fluid apical plasma membrane surfaces because, when activated to secrete acid, abundant vesicles rapidly fuse with each other and, ultimately, the plasma
A

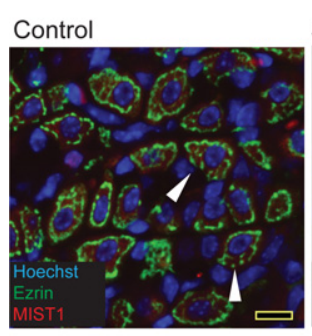
Atp $4 b^{\text {Cre }} ;$ LSL-MIST1 ${ }^{\text {myc }}$

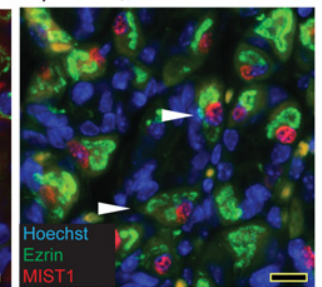

B

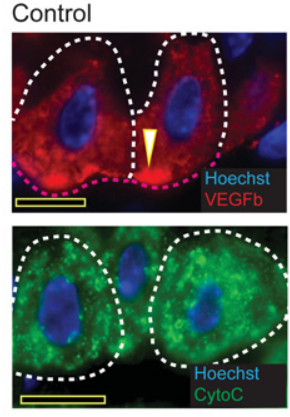

Atp $4 b^{\text {Cre }} ;$ LSL-Mist1 ${ }^{\text {myc }}$
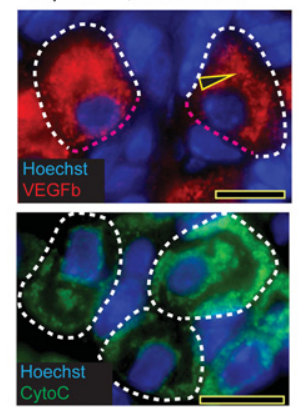

D
C

\section{Nuclear Position}

(Relative to cell diameter)
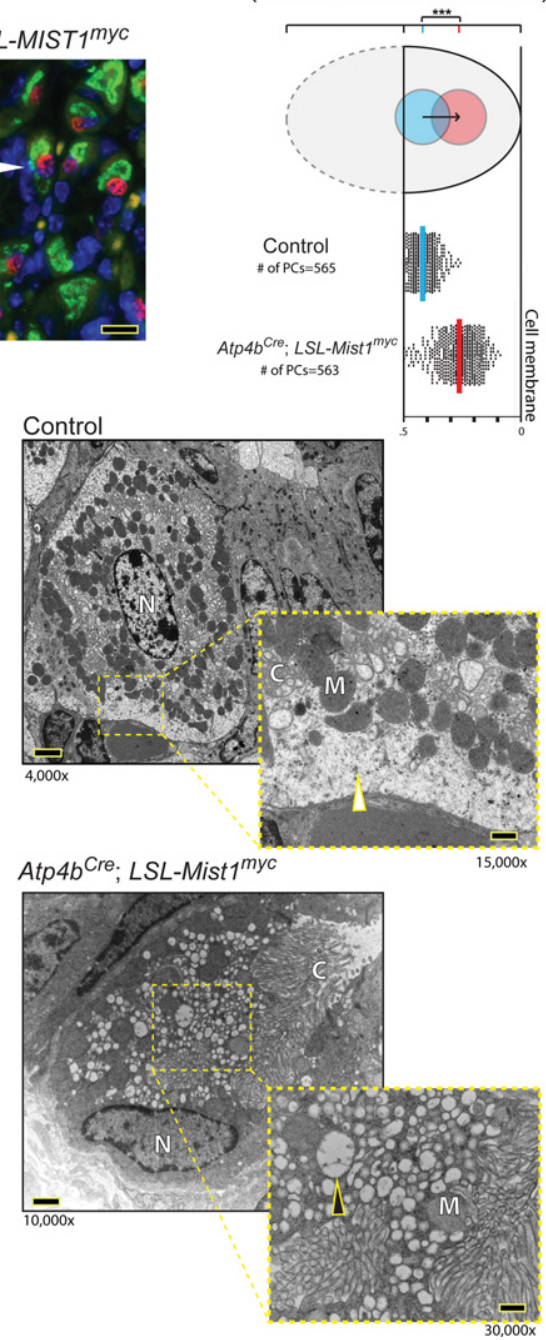

Figure 3. MIST1 is sufficient to induce changes phenocopying secretory architecture in gastric PCs, which do not normally express MIST1. (A) Representative images of PCs (white arrowheads) of the control (left) and MIST1-expressing Atp $4 b^{\text {Cre }}{ }_{\text {iLSL-Mist } 1}{ }^{\text {myc }}$ mutant (right). PCs are identified by prominent staining with the apical membrane marker ezrin (green) and antibody versus endogenous MIST1 protein (red) to confirm ectopic expression in mutant cells. (B) Representative immunofluorescence showing that, in control PCs, VEGFB granules (red) normally concentrate at the membrane surface immediately opposite capillaries (white arrowhead), mitochondria (green) are distributed diffusely throughout the cytoplasm, and nuclei (blue) are centrally located. In MIST1-PCs, VEGFB concentrates in the expanded cytoplasmic region opposite the eccentrically localized nucleus, with mitochondria forming two crescents: one just adjacent to the nucleus and the other more peripheral. VEGFB granules (black arrowhead) fill the region between the two crescents, which is also where the abundant apical membrane (labeled by ezrin but not shown in these images) concentrates. $(C)$ Quantification of nuclear position showing that nuclei in MIST1-PCs (red) move $38 \% \pm 1 \%$ closer to the cell border $(n=4 ; P<0.001)$ than control PCs (blue). Significance was determined using a one-tail Student's $t$-test. $(D)$ Transmission electron microscopy (TEM) highlighting the dramatic reorganization of the interdigitating apical membrane surface (known as canaliculi [ " $\mathrm{C}$ "] and labeled with ezrin in $A$ ) to the side of the cell opposite the nucleus in MIST1PCs. Note also the accumulation of large secretory granules harboring scant electron-dense proteinaceous material (black arrowhead) adjacent to the canaliculi and relocation of the nucleus $\left(" \mathrm{~N}^{\prime \prime}\right)$ and mitochondria (" $M$ "). Note that, in control PCs, the region where VEGFB localizes is in fine granules just opposite a capillary surface (note the erythrocyte at the base of the white arrowhead and the fine granules at the point of the arrowhead). Bars: $A, 10 \mu \mathrm{m}$; $B$, $20 \mu \mathrm{m} ; D, 2 \mu \mathrm{m} ; D$, inset, $600 \mathrm{~nm}$. 
membrane (Forte et al. 1977) to expand the surface area for transmembrane $\mathrm{H}^{+}-\mathrm{K}^{+}$-ATPases to pump acid into the lumen. Ezrin marks the dynamic, fluid subapical membrane and interacts with cortical F-actin (Hanzel et al. 1991). PCs have complex interactions with a rich capillary network that does not have a strict orientation with respect to the gastric unit lumen and have fluid interactions with neighboring cells such that the epithelium in the neck of the gastric unit, where PCs arise, adopts more of a pseudostratified morphology (Bredemeyer et al. 2009). The fluid dynamic nature of the PC apical membrane and the fluid cell-cell and cell-basement-membrane contacts result in PC nuclei adopting a central position within the cell (Fig. 3A). The complex apical membrane network interdigitates inward from the lumen, diving into the cell cytoplasm in no specific orientation with respect to other cells or capillaries, thereby forming an intracellular ring-like structure in most cross-sections (Fig. 3A).

We showed previously that PCs express VEGFB at their basolateral surface (Bredemeyer et al. 2009; Capoccia et al. 2009). Here, we show that the VEGFB is largely concentrated within small $(<300-\mathrm{nm})$ vesicles near the PC plasma membrane surface that borders capillary vessels distal from the apical membrane-associated region (Fig. 3B).

MIST1-PCs ( $n=8$ mice) have markedly rearranged architecture. They adopt a nuclear and secretory granule arrangement that phenocopies that of MIST1-expressing regulated secretory cells. For example, MIST1-PCs accumulate VEGFB near the apical membrane rather than near the capillary surface (Fig. 3B). In Figure 3B, staining for mitochondria, which are excluded from the ezrin ${ }^{+}$apical membrane zone, highlights in relief that VEGFB becomes concentrated in this portion of the cell. Transmission electron microscopy (TEM) confirmed that MIST1-PCs lose their zone of small granules near capillaries (Fig. 3D, white arrowhead) in favor of collections of large granules (Fig. 3D, black arrowhead) near the interdigitating apical membrane complex (Fig. 3D). In immunogold EM, these apically redistributed granules mark with anti-VEGFB (Supplemental Fig. S3A,B). Like regulated secretory cells expressing MIST1, the nucleus in MIST1-PCs repositions in a polarized fashion away from the ezrin-staining apical membrane region and the VEGFB granules (Fig. 3C). Thus, MIST1-PCs form abundant expanses of cytoplasm apical to the nucleus, filled with secretory granules, similar to $\mathrm{MIST}^{+}$exocrine secretory cells such as those of the stomach, salivary glands, and pancreas.

In TEM micrographs and immunofluorescence (Fig. 3B, D), we noticed that, whereas mitochondria in control PCs were distributed throughout the cytoplasm, the mitochondria in MIST1-PCs were organized in two distinct crescents: one around the nucleus and one underneath the apical plasma membrane opposite the nucleus. We also noticed that lysosomes in control PCs in TEM were roughly circular in cross-section, relatively abundant, and nearly always in contact with mitochondria (Supplemental Fig. S4A), whereas those in MIST1-PCs were smaller and more irregular (Supplemental Fig. S4B).
To further analyze the dramatic reorganization of PC architecture induced by MIST1, we undertook a three-dimensional (3D) nanotomography analysis using focused ion beam-scanning EM (FIB-SEM) (Fig. 4; Supplemental Movies S1A, S2A). FIB-SEM imaging of control PCs showed how the mitochondria were evenly distributed throughout the cytoplasm in an intricate mazy network (Supplemental Fig. S4C; Supplemental Movie S1C). Lysosomes were abundant, roughly spherical, and seemingly randomly distributed throughout the cytoplasm but almost always in direct apposition to mitochondria (Supplemental Fig. S4A,C; Supplemental Movie S1D). Control PC nuclei were almost always positioned within the central portion of the cell with respect to cell-cell contacts, cell-basement membrane contacts, and the gastric unit lumen; they were ovoid with smooth contours (Supplemental Movie S1B). Abundant capillaries wrapped around each PC such that cells had unclear polarity with respect to capillaries and lumens. MIST1-PCs, on the other hand, had a more polarized orientation, with nuclei eccentrically positioned, often apposing capillaries (Supplemental Movie S2B). They had mitochondria organized in crescents opposite the nucleus (Supplemental Fig. S4C; Supplemental Movie S2C). Their lysosomes were sparser, more irregular, and often not directly apposed to mitochondria (Supplemental Fig. S4C; Supplemental Movie S2D). MIST1-PC nuclei were oblong with irregular contours (Supplemental Movie S2B).

The 3D analyses also confirmed the secretory granule phenotype in MIST1-PCs. Many of the lysosomes were located in between the perinuclear and apical plasma membrane rings of mitochondria, but, most prominently, there were abundant granules with the same morphology seen on TEM and immunogold in this region between the mitochondrial bands (Fig. 4B; Supplemental Movie S2E). Such apical granules in control PCs were rare and smaller than those seen in MIST1-PCs (Fig. 4A; Supplemental Movie S1E). We measured secretory granule size in all three dimensions to discover that their volume was substantially increased in MIST1-PCs (Fig. 4C).

In our examination of Atp4b-Cre; LSL-Mist $1^{\text {myc }}$ mice, we noticed that occasional PCs did not show detectable MIST1-myc. We compared PCs expressing the Mist1myc transgene (MIST1-PCs) with these rare cells that did not in the same sections. MIST1 expression correlated highly significantly with the eccentric nuclear position, indicating that the architectural rearrangements of PCs in Atp4b-Cre; LSL-Mist $1^{\text {myc }}$ mice are directly correlated with MIST1 expression (data not shown). In other experiments, we ablated nearly all PCs by three consecutive daily injections of toxic amounts of tamoxifen (5 mg per $20 \mathrm{~g}$ of body weight) (Huh et al. 2012). We studied the newly re-emerging MIST1-PCs at day 7 following the first tamoxifen injection. These newly formed PCs were much more frequently MIST1-mycnegative. Those lacking MIST1 had wild-type nuclear positioning, and those that had already showed immunofluorescent-detectable MIST1 had the morphology typical of MIST1-PCs (Supplemental Fig. S5A,B). Thus, all of the data are consistent with MIST1 expression being 


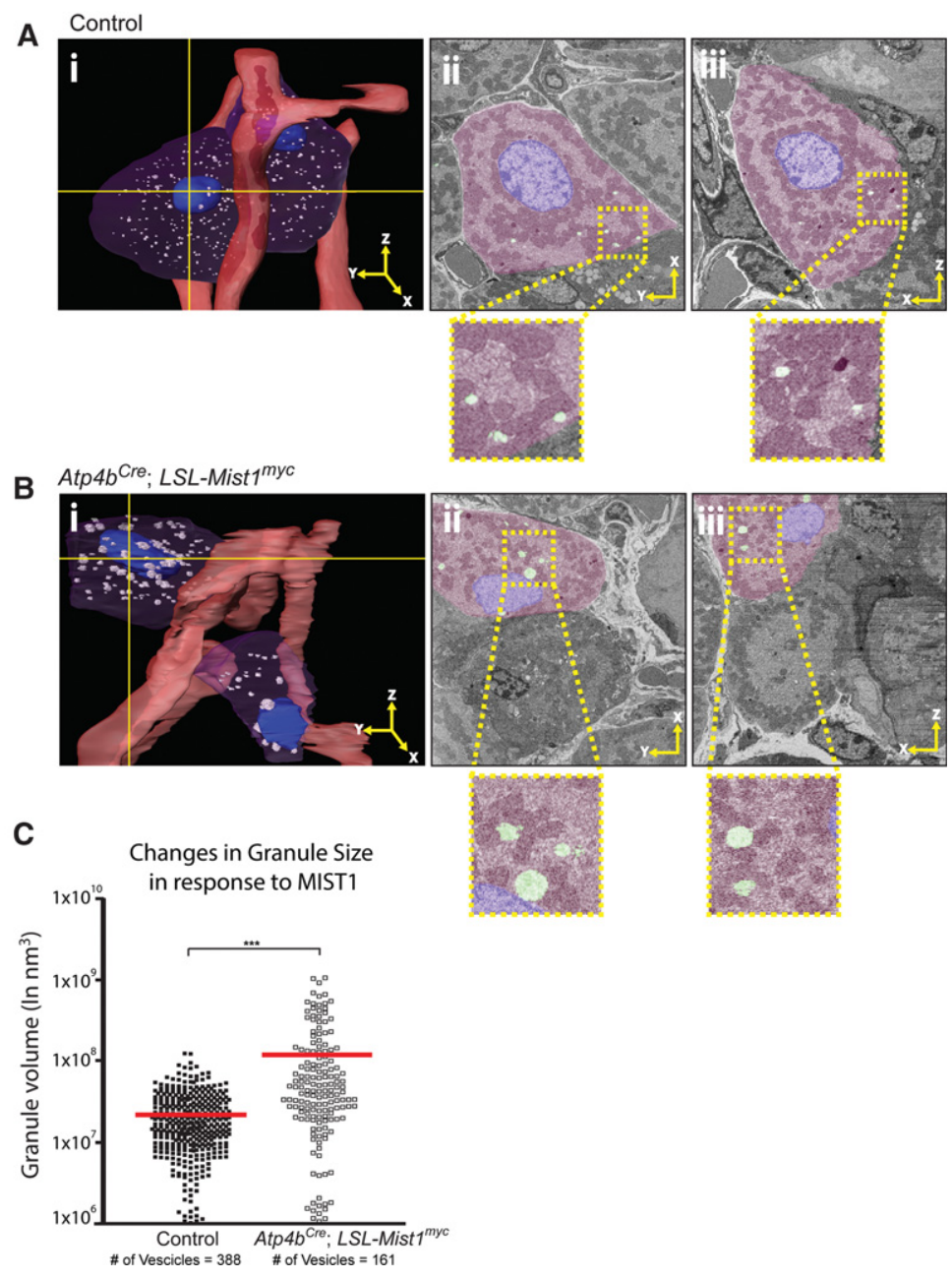

Figure 4. MIST1 is sufficient to induce large apical granules. $(A, B$, panel i) $\mathrm{A} 3 \mathrm{D}$ rendering reconstructed from 2000 individual EM slices taken from SEM images from a FIB-SEM experiment depicting a portion of the neck zone of a gastric unit with wild-type $(A)$ and Atp4bCre,LSL-MIST1myc (B) PCs (purple), capillaries (red), and vesicles (white). The two intersecting lines (panel i) represent the placement of the orthogonal slice of the featured cell visualized in the XY (panel ii) and XZ (panel iii) coordinate planes. $(C)$ Quantification of granule volume (i.e., using all three dimensions) showing that the Atp4bCre;LSL-MIST 1 myc PCs are 5.2-fold \pm 0.44 -fold larger.

directly correlated with the architectural changes in a cell-autonomous mechanism.

Finally, we aged a cohort of mice (9-12 mo old) to test the long-term effects of forced MIST1 expression in PCs. MIST1-PCs maintained their exocrine cell-like architecture (Supplemental Fig. S5C). Thus, Mist1 is sufficient to alter the cellular architecture of PCs continuously throughout the lives of individual PCs and the mice in which they are found.

In Figure 5, we summarize the most dramatic changes in cell shape that are seen in both a loss-of-MIST1 and gain-of-MIST1 setting by tracing over TEM images of a cell representative of each genotype.

\section{Ectopic expression of MIST1 in other cell types phenocopies changes induced in PCs}

To determine whether forced expression of MIST1 sufficed to induce similar architectural rearrangements in other cell types, we first overexpressed Mist1 in organoids derived from the gastric corpus. To do this, we used antibiotic resistance to select clones from LSL-MIST1 ${ }^{\mathrm{myc}}$; ROSA $26^{\mathrm{mTmG}}$ "gastroids" that had been transfected with a plasmid encoding antibiotic resistance genes and tamoxifen-inducible Cre recombinase. Low-dose 4-OH tamoxifen treatment (higher doses are toxic) (Burclaff et al. 2016) induced expression of MIST1 chimerically throughout the culture (Supplemental Fig. S6A), allowing us to directly compare cells expressing Mist1 with control neighboring cells in the same well. Organoids were grown in an extracellular matrix without much tensile strength (Matrigel) in the absence of basal connective tissue. Thus, there were few constraints on cells along the apical-basal vector. Nevertheless, within the limitations of the system, MIST1 did cause marked changes in cell architecture: MIST1 nuclei were more irregular, and cytoplasms were more expansive, while control cells formed an ordered, homogeneous, columnar-cuboidal monolayer (Supplemental Fig. S6A, cf. white and black arrowheads). We speculate that the apical contraction induced by MIST1 caused cells simply to flatten and expand laterally, as they faced little countervailing cellular or connective tissue basolateral force in the soft Matrigel. As expected, MIST1 expression did not govern cell differentiation (MIST1 ${ }^{+}$cells showed no change in cell lineage markers) (data not shown).

We next sought to induce Mist 1 by expression of a plasmid encoding Cre in vivo. We injected AAV8-TBG-iCre 


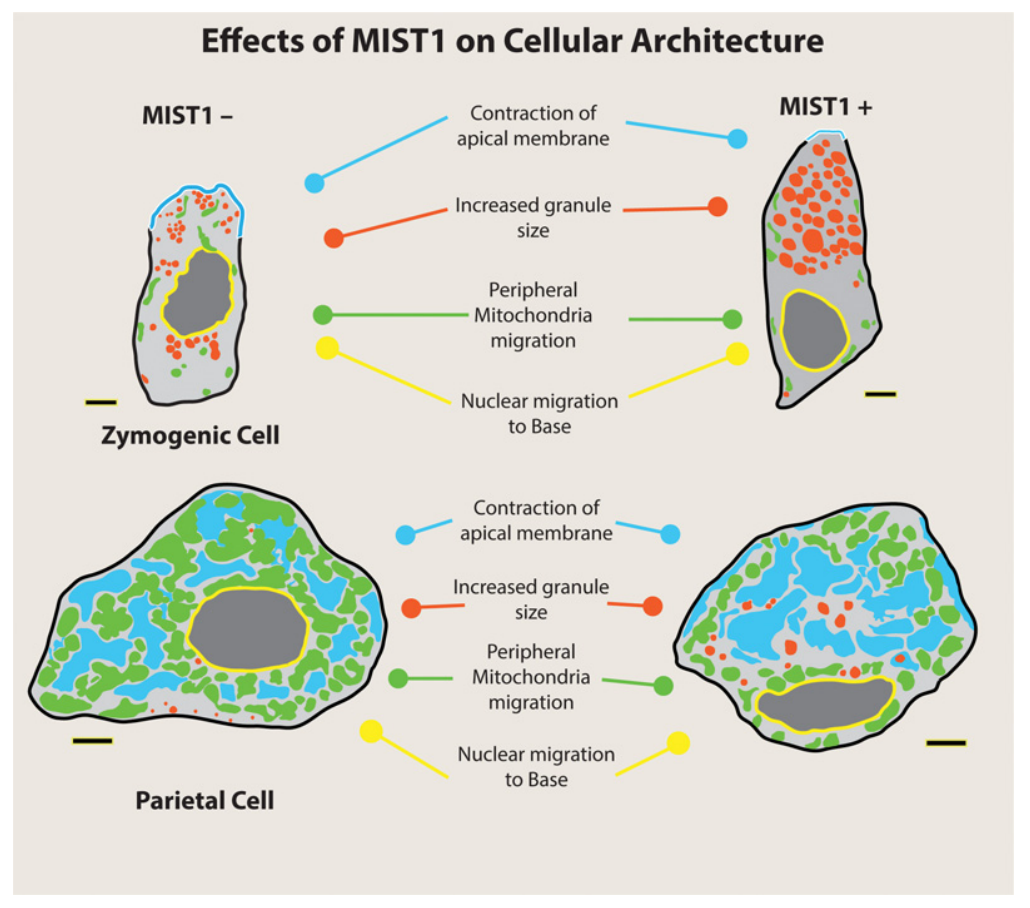

Figure 5. Summary of MIST1-dependent architecture changes from gain-of-function and loss-of-function experiments. Cells were traced from TEM images. Bars, $2 \mu \mathrm{m}$.

intraperitoneally into adult LSL-Mist $1^{\text {myc }}$ mice $(n=5$ mice total) and controls $(n=3)$ in two independent experiments. In one of three mice in the first experiment and two of two in the second, Cre recombinase transduction caused abundant ectopic Mist1 transcript and protein expression within 2 wk (Supplemental Fig. S6B). Note that adult hepatocytes normally express no detectable endogenous MIST1 protein and negligible mRNA. As expected, MIST1 did not affect hepatocyte differentiation, as all hepatocytes maintained differentiated markers such as albumin and apoE by immunofluorescence and had unchanged expression of a-fetoprotein and $H n f 4 a$ mRNA transcript levels by quantitative PCR (qPCR) (data not shown). Tissues from the three mice across two experiments with $>90 \%$ ectopic MIST1 expression (Supplemental Fig. S6B) were used to determine the effects of MIST1 in subsequent analyses. MIST1 ${ }^{+}$(Supplemental Fig. S6B, black outline) cells were easily distinguishable from control hepatocytes (Supplemental Fig. S6B, blue outline) by their dense eosinophilic central cytoplasm and peripheral vesicles (Supplemental Fig. S6B). MIST1 ${ }^{+}$cells were more complex in shape and asymmetric (statistically significant decrease in "circularity" metric of cells in Image J analysis, $P$-value $<0.001)$. Examining the GFP induced by Cre recombinase action on the ROSA26 $6^{L S L-m T m G}$ allele allowed us to analyze differences in membrane organization in control mice versus $\mathrm{MIST1}^{+}$mice (Supplemental Fig. S6D). $\mathrm{MIST}^{+}$hepatocytes accumulated large peripheral vesicles (Supplemental Fig. S6C, yellow arrows), whereas controls had smaller more central vesicles (Supplemental Fig. S6C, red arrow).

Hepatocytes are large cells with complex multidimensional orientation: Their apical bile ductular and basolateral capillary sinusoidal aspects are difficult to orient in two-dimensional sections. Nevertheless, even in standard
5 - $\mu \mathrm{m}$ tissue sections, it was evident that MIST1 altered hepatocyte nuclear position (Supplemental Fig. S6C). Control hepatocytes almost always had central nuclei, with only $4 \%$ having a nucleus within the peripheral third of the cell, whereas over a quarter of MIST1 hepatocytes had such eccentric nuclei ( 77 out of 272 cells). The analysis was performed blinded to the actual level of ectopic expression of MIST1 in each cell (Supplemental Fig. S6B), but, even without correcting for that possible confounder, MIST1-induced marginalization of the nucleus was highly statistically significant (Supplemental Fig. S6D).

A core group of MIST1 targets is regulated across multiple cell types, including in PCs ectopically expressing MIST1

Our results so far indicated that MIST1 alone is sufficient to govern core features of secretory cells even in an ectopic setting (i.e., without adding cofactors), indicating that it can act as a master regulator of secretory cell architecture. We next sought to examine MIST1-regulated gene expression in multiple tissue settings to identify some of the genes that MIST1 uses to induce its characteristic cellular reorganization. Many transcriptional targets that MIST1 activates directly have been identified in the past, whereas targets repressed by MIST1 have not been well characterized, so we confined our analysis to MIST1-induced genes.

We performed previous studies that identified a core cohort of MIST1-induced transcripts in cells that normally express MIST1 in the stomach (ZCs) and pancreas (acinar cells). The most robust of these identified genes were expressed in wild-type pancreata, lost in Mist1 ${ }^{-/-}$pancreas, and rescued by induced expression of MIST1 in the Mist1null background (Direnzo et al. 2012). We and our collaborators also recently performed ChIP-seq (chromatin 
immunoprecipitation [ChIP] combined with highthroughput sequencing) of MIST1 binding in pancreatic acinar cells (Jiang et al. 2016). We performed Affymetrix GeneChip microarray analysis of whole stomachs from MIST1-PC and control mice and identified the list of genes that were statistically significantly increased in both MIST1-PCs versus control and in pancreatic acinar cells. This analysis yielded a list of 36 putative MIST1-regulated genes in both gain-of-function and loss-of-function experiments in different organs (Supplemental Fig. S7A).

To determine whether there were any obvious patterns to the cohort of genes, we performed DAVID functional clustering (Huang et al. 2009a,b). Of the 30 genes with gene ontology annotations for cellular components, $24(80 \%)$ were annotated as "intracellular membranebound organelle," and 27 (90\%) were annotated with "intracellular part" (Supplemental Table S2). Those terms were highly statistically significant relative to their occurrence in the transcriptome as a whole $144 \%$ and $56 \% ; P<$ 001). Only 11 out of 30 (37\%) were annotated as "nucleus," which was not statistically different from the expected occurrence of this term $(28 \%)$ in the transcriptome as a whole. The "nucleus" transcripts were all also classified as "intracellular membrane-bound organelle." Thus, the targets potentially governed by MIST1 are largely localized to organelles, as opposed to secreted or cytoskeletal cellular components, consistent with the phenotype of reorganization of organelles that we observed.

To further prioritize our list of MIST1 targets, we first determined the MIST1-dependent expression of each transcript in our previously published GeneChip analysis of laser-captured ZCs (Capoccia et al. 2013). In this experiment, GeneChips were generated from isolated ZCs and their precursor mucous neck cells in Mist $^{-/-}$and control mice. MIST1 is not expressed in neck cells, only during the transition from neck cells to ZCs (Ramsey et al. 2007). Highly MIST1-dependent genes would thus be expressed at higher levels in wild-type ZCs relative to both wild-type neck cells and Mist $1^{-1-}$ ZCs. The overlapping genes are listed in Figure 6A. Two of the genes were expressed higher in wild-type versus Mist1 ${ }^{-1-}$ ZCs but still had high expression in mucous neck cells (lighter-green bar in Fig. 6A).

We next reasoned that MIST1 targets that govern the secretory apparatus independent of cell lineage would likely overlap in expression with MIST1 in multiple tissues. We used archived unbiased microarray data to determine the tissues with the top 10 highest levels of expression of MIST1 and each target (see the Materials and Methods). All transcripts for which three or more of the top 10 tissues of the highest expression overlapped with MIST1 are shown also in Figure 6A. Next, we filtered for genomic sequences within the first intron of each target gene for $\mathrm{E}$ boxes conserved across multiple vertebrate species (Fig. 6A). We also analyzed raw ChIP-seq analysis of MIST1 occupancy in wild-type pancreatic acinar cells from our collaborator (Jiang et al. 2016). We determined which of the MIST1 targets had significant MIST1 binding within $4 \mathrm{~kb}$ of the transcription start site (TSS). Twentythree of our starting list of genes met at least one of these additional filters. Finally, we performed Affymetrix GeneChip analysis on MIST $1^{+}$hepatocytes and control cells and determined which of the targets had statistically significant increased expression. Figure 6A ranks the putative MIST1 targets in decreasing order of fulfilling the filtering criteria. Two genes in the list, Rab26 and Copz2, have been shown previously to be direct targets of Mist1 (Tian et al. 2010; Direnzo et al. 2012; Jin and Mills 2014). Thus, we identified multiple core transcriptional targets of MIST1 that meet the following criteria: (1) Their expression is regulated by MIST1 in multiple organs, (2) their genes' regulatory elements are occupied by MIST1, (3) their expression is increased in in vivo gain-ofMIST1-function experiments, (4) their expression is decreased in in vivo loss-of-MIST1 experiments, (5) they are coexpressed in tissues where MIST1 is highly expressed, and (6) they are known to have function and localization consistent with roles as cellular effectors to induce and maintain cellular secretory architecture.

We and others have shown that both MIST1 and its Drosophila ortholog, DIMMED, prefer binding to palindromic CATATG or CAGCTG E boxes, usually located within the first kilobase of the first intron of target genes (Park et al. 2008; Garside et al. 2010; Tian et al. 2010; Direnzo et al. 2012; Hadzic et al. 2015). Using the ChIP-seq analysis of MIST1 binding to acinar cell genomic DNA, we analyzed the location of the significant peaks in our list of putative target genes. Fifteen of our 23 putative genes had at least one significant MIST1 ChIP-seq peak within 4500 base pairs (bp) of the TSS using our filtering criteria. Overall, there were 36 such peaks, the vast majority of which (32 out of 36) was downstream from the TSS, most of these being within the first intron (and, occasionally, if the first exon and intron were $<4500 \mathrm{bp}$, within the second intron) (Fig. 6B). A motif screen using MEME suite (Bailey and Elkan 1994) of an unbiased search of recurring DNA patterns (peak sequences analyzed ranged from 200 to $711 \mathrm{bp}$ within the 36 peaks) identified a recurring "CCANNTG" core element, where the NN are most commonly GC or, slightly less commonly, TA (Supplemental Fig. S7B).

All of the analyses were thus consistent with our cohort of genes being enriched for MIST1 targets because the previously identified preferred E boxes for MIST1 (CAGCTG and CATATG) were highly enriched in both our list of targets and where MIST1 bound in available ChIP-seq data (Supplemental Fig. S7B). When examining all of the putative targets for conserved E boxes, we noticed an unusual feature of the target genes bound by MIST1 that has not been described previously. One of the mirror image palindromic E boxes, CAATTG, was nonrandomly excluded from the MIST1-binding peak regions in our MIST1bound putative targets $(P<0.05)$ (Fig. 6B). To determine whether this nonrandom occurrence of CAATTG within MIST1-binding regions held true in a large data set, we examined the 250 significantly induced MIST1 targets in the acinar cell data set (see the Materials and Methods). Within the MIST1-bound stretches of DNA in those genes (214 genes had significant MIST1-bound peaks), there were 259 CAGCTG E boxes but only three CAATTG sequences 
A

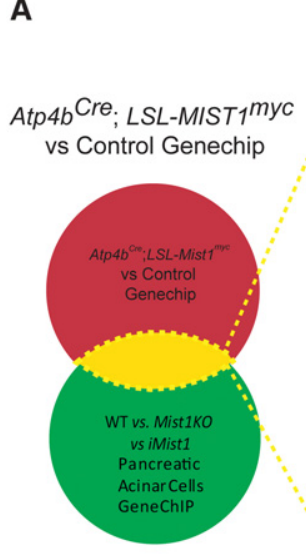

\begin{tabular}{|c|c|c|}
\hline \multicolumn{3}{|c|}{$\begin{array}{l}\text { Core Cohort of Candidate MIST1 targets } \\
\text { Dependent on MIST1 in ZCs } \\
\text { High conservation putative MIST1 site } \\
\text { ChIP-Seq significant peaks } \\
\text { Co-expressed substantially with endogneous MIST1 throughout body } \\
\text { Upregulated in ectopic MIST1 hepatocyte expression }\end{array}$} \\
\hline 5330417C22Rik & Trabd & \\
\hline Bckdk & Dixdc1 & \\
\hline Copz2 & Itga1 & \\
\hline Gcdh & Ttc7b & \\
\hline Ufm1 & Tmed6 & \\
\hline Wdyhv1 & Pon3 & \\
\hline Large2 & Paip2b & \\
\hline Rab26 & Nudt22 & \\
\hline Aass & Qpctl & \\
\hline Ostm1 & Cep76 & \\
\hline Qtrt1 & Dusp22 & 111 \\
\hline Tmem219 & & \\
\hline
\end{tabular}

B Spatial Distribution of ChIP-Seq CANNTG Sites of Candidate Genes

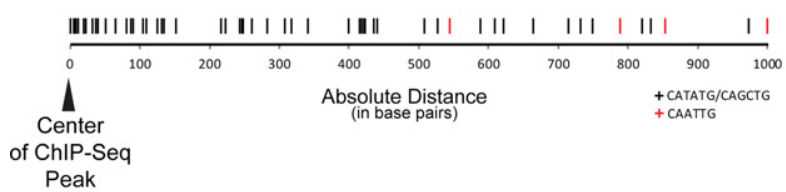

CANNTG Motifs enriched in ChIP-Seq peaks

\begin{tabular}{|l|c|c|c|}
\hline \multicolumn{1}{|c|}{ Motifs } & $\begin{array}{c}\text { Motif Counts } \\
\text { in ChIP-Seq peaks } \\
\text { in 214 genes }\end{array}$ & $\begin{array}{c}\text { Motif counts per } \\
\text { X bp of DNA }\end{array}$ & $\begin{array}{c}\text { Fold change of } \\
\text { motifs enriched in } \\
\text { ChIP-Seq peaks }\end{array}$ \\
\hline CAGCTG & 259 & 57 & 4.5 \\
\hline CATATG & 86 & 19 & 4.5 \\
\hline CACGTG & 25 & 14 & 1.8 \\
\hline CAGATG/CATCTG & 101 & 60 & 1.7 \\
\hline CAACTG/CAGTG & 40 & 33 & 1.2 \\
\hline CACCTG/CAGGTG & 87 & 76 & 1.1 \\
\hline CACATG/CATGTG & 56 & 53 & 1.1 \\
\hline CACTTG/CAAGTG & 43 & 46 & -0.9 \\
\hline CATTTG/CAAATG & 42 & 49 & -1.2 \\
\hline CAATTG & 3 & 8 & -2.6 \\
\hline
\end{tabular}

Figure 6. MIST1 regulates a cassette of genes based on gain-of-function and lossof-function experiments in diverse tissues. (A) Genes significantly increased in both (1) pancreatic acinar cell loss-of-function and rescue microarray data sets and (2) MIST1-PC versus control stomachs were determined. That gene list was further filtered according to the criteria at the right (dependence on MIST1 in gastric chief cells, evolutionarily conserved MIST1 Ebox site within promoter or early intronic region, possession of a MIST1-bound ChIP-seq site in pancreatic acinar cells, shared tissue expression pattern with MIST1, and up-regulated in ectopic MIST1-expressing hepatocytes by Affymetrix GeneChip). The 23 genes meeting at least one of those criteria are depicted in decreasing order of potential MIST1 dependence. Note that probes for Large2 were not present on the Affymetrix GeneChip microarrays used for the ZC experiment. (B) All E boxes of either MIST1 canonical CATATG/CAGCTG or noncanonical CAATTG type that occur within ChIP-seq peaks of the 23 genes in $A$ are plotted as a function of absolute value distance in base pairs from the ChIP-seq peak. Note the frequency of CATATG/CAGCTG sites near the peak, the rareness of CAATTG motifs within $1 \mathrm{~kb}$, and the complete exclusion within 500 base pairs (bp). CATATG/ CAGCTG sites are $13.5 \times$ higher than CAATTG sites to appear within $1 \mathrm{~kb}$ of the ChIP-seq peak. $P<0.03$, by Fisher's exact test. $(C)$ The table shows the absolute counts of each CANNTG motif in 214 of the pancreatic acinar genes whose expression was dependent on MIST1 and that also had MIST1 ChIP-seq peaks within the promoter-early intron region (the first column). For the second column, this count was normalized to account for differing lengths of called ChIP-seq peaks so that frequency per equivalent length of DNA was calculated. This figure was used to determine enrichment within the peak of the given E-box motif relative to the frequency of the motif in the $1 \mathrm{~kb}$ of DNA flanking each ChIP-seq peak. The relative enrichment within the peak (normalized per 6-bp stretches of DNA) relative to the frequency in the flanking sequences is shown in the third column.

(Fig. 6C). Compared with surrounding DNA not bound by MIST1, CAGCTG sites were 4.5 -fold enriched within the MIST1-bound region, whereas CAATTG sites were 2.6fold less commonly found within MIST1-bound peaks (Fig. 6C). This nonrandom distribution was highly statistically significant $(P<0.0001)$.

\section{Validation of new MIST1 targets}

We next performed qPCR for our putative MIST1-regulated genes on whole Atp $4 b-C r e ;$ LSL-Mist ${ }^{\text {myc }}$ versus control Atp4b-Cre stomachs ( $n=4-9$ mice per genotype) (Fig. 7A). Twenty-one out of 23 genes showed, on average, increased expression in MIST1-PC mice ( $n=4-9$ mice); 10 of these changes were statistically significant (it should be kept in mind that, for a number of reasons, this assay is highly skewed toward false negatives [see the Discussion] such that genes whose expression was not statistically significantly different may still be MIST1-regulated in PCs).

We further validated our gene targets in $\mathrm{MIST}^{+}$hepatocytes. In yet another cellular context, forced expression of MIST1 alone was sufficient to up-regulate expression of 19 out of 23 of the putative architecture-regulating target genes. Expression of five genes (5330417C22Rik, Tmed6, Large2, Cep76, and Ufm1) was significantly induced by extopic MIST1 in a reproducible fashion in both stomach and liver qPCR (Fig. 7A).

We were able to acquire antibodies against two of the MIST1 targets significantly up-regulated in two different gain-of-function and multiple loss-of-function experiments: the minimally characterized gene 
A

Relative expression of putative targets by qPCR (MIST1 overexpression vs. control)

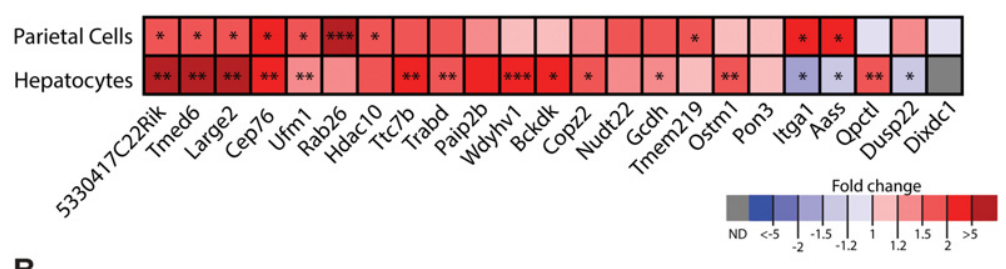

B

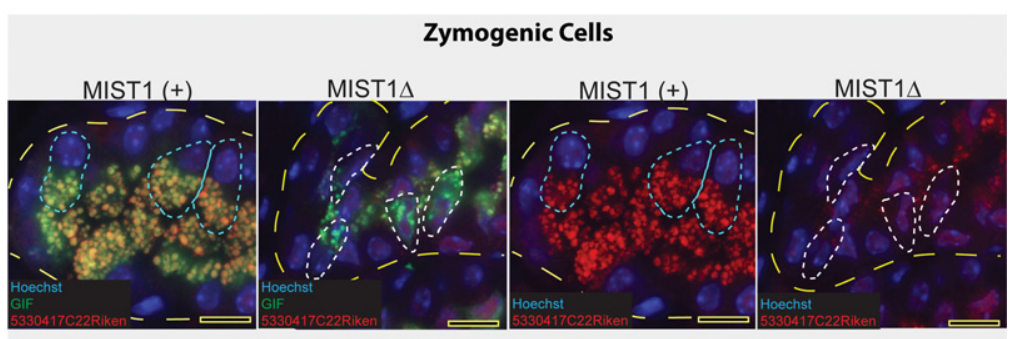

C
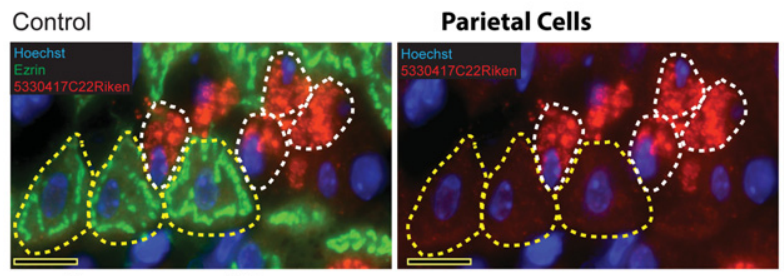

Atp $4 b^{\text {Cre }} ;$ LSL-Mist1 ${ }^{\text {myc }}$
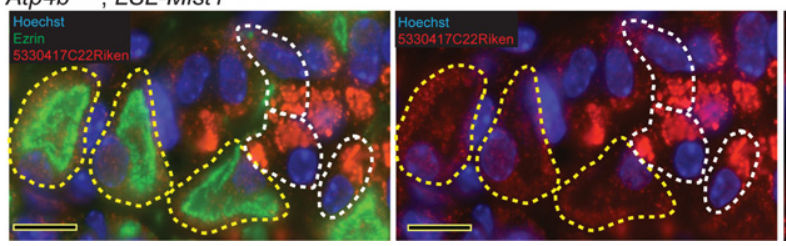

Figure 7. A previously uncharacterized MIST1 target is decreased in MIST1 loss of function and increased in MIST1 gain of function. (A) A heat map depicting the relative fold change from control of the 23 candidate genes in MIST1-expressing cells of the stomach and the liver determined with qRTPCR. $\left(^{*}\right) P<0.05$; $\left(^{* *}\right) P<0.01$; $\left(^{* *}\right) P<0.001$, significance by one-tailed, paired $t$-test. (B) 5330417C22Riken protein in the ZCs of the stomach within $\mathrm{MIST1}^{+}$(dashed blue outline) and induced MIST1 deletion MIST1 $\Delta$ (as per Fig. 1, dashed white outline). ZCs are identified by green GIF granules. (C) 5330417C22Riken (red) in ZCs (white dashed outline) and PCs (yellow dashed outline). MIST1-PC and control stomachs were taken at the same camera exposure setting (note the same expression of the protein within ZCs that are wild type in both animals). Insets show an enlarged image of a PC, with autocontrast applied to expose the PCs without ZCs in the frame. Note that MIST1-PCs have far more intense staining than control PCs, which are only slightly above background. Also, intracellular distribution of protein is more widespread within MIST1-PC cytoplasm. Bars, $10 \mu \mathrm{m}$.
5330417C22Rik (human ortholog KIA1324, also known as estrogen-induced gene 121) (Deng et al. 2010) and the ER stress-associated gene UFM1 (Lemaire et al. 2011; Hu et al. 2014). UFM1 was highly specific to ZCs in control stomachs and absent from ZCs in the Mist $1^{\text {CreERT2/A }}$ mice 2 wk after induction of tamoxifen to delete MIST1 (Supplemental Fig. S8A). Furthermore, in Atp4b-Cre; LSL-Mist $1^{\text {myc }}$ mice, a distinct pattern of UFM1 staining was observed in the vast majority of MIST1-PCs (namely, those that had the morphological changes induced by MIST1), whereas control PCs showed only diffuse background staining (Supplemental Fig. S8B). Quantification of staining intensity showed increased Ufm1 staining in MIST1-expressing PCs (Supplemental Fig. S8B). Antibodies to the minimally characterized protein 5330417C22Riken showed both loss of this protein following ablation of MIST1 in ZCs and induced expression within MIST1-PCs (Fig. 7B,C). We noted further that intracellular distribution of this protein was different in MIST1-PCs. In controls, it more or less resembled the pericapillary surface expression of VEGFB, whereas, in MIST1-PCs, it redistributed to the cell periphery (Fig. 7C).

\section{Discussion}

Here, we showed that a single transcription factor, MIST1, scales a series of cell architectural features that govern regulated secretion. Withdrawal of MIST1 in cells that normally express it leads to loss of secretory architecture. Ectopic expression in cells that do not normally express MIST1 is sufficient for complete rearrangement of cell architecture. Neither gain nor loss of function alters cell fate or identity; all of the effects that we saw were confined to cell architecture.

Thus, we argue that the present study answers a sort of Koch's postulates for how a single transcription factor might govern the subcellular machinery responsible for secretory cell architecture in cells in tissue. We show (1) where MIST1 is abundantly expressed in exocrine secretory cells throughout their life, (2) that taking away MIST1 from those cells rids them of their characteristic secretory architecture, (3) that introducing it into nonMIST1-expressing cells that do not have an exocrine cell organization induces one in the new cells, and (4) that the target genes that are in common in both the newly 
induced cells and the normal MIST1-expressing cells are overlapping, suggesting that MIST1 is working the same way in both cases.

In the past, we proposed that MIST1 is a prototype of an evolutionarily conserved category of transcription factors that we dubbed scaling factors (Mills and Taghert 2012). These transcription factors would scale specific subcellular features so that adult cells could specialize to perform specific tasks with high efficiency (Mills and Taghert 2012). We predicted several aspects of scaling factor function: (1) Scaling factors would be up-regulated in terminal differentiation of cells but would not affect their fate or function, just the efficiency with which they perform that function. (2) They would not govern expression of cell lineage-specific genes (i.e., the types of genes used to distinguish one cell lineage from another, such as PGC in $\mathrm{ZCs}$ and $\mathrm{H}^{+}$- $\mathrm{K}^{+}$-ATPase in PCs). (3) They would not induce expression de novo of genes but rather scale up genes that are more or less ubiquitously and constitutively expressed at lower levels in most cells. Thus, the target genes of scaling factors would fall under the loose rubric of "housekeeping genes" that are relatively broadly expressed. (4) Scaling factors would scale up a subset of these genes so that the cell would divert a higher proportion of its resources to ramp up a specific cellular function. In the case of MIST1, all cells secrete; MIST1 scales up the cellular apparatus to make a cell a veritable secretory factory. (5) Because a scaling factor simply increases expression of genes that are already expressed, it may be sufficient by itself to rearrange cellular architecture if expressed ectopically in other differentiated cells.

We further hypothesized that scaling factors may have been selected with these features because they would afford evolution an easy way to confer entire cellular functional phenotypes in new cellular contexts. This would be an advantage because most commonly studied transcription factors involved in cell differentiation are regulated within a specific spatiotemporal developmental context-a sequence of germ layer, then organ, then tissue, and then cell-specific expression (Edlund and Jessell 1999). They also seem to operate restricted to a specific cellular context, often needing other cofactors specific to that cell to function. Thus, it is striking that MIST1-expressing PCs and hepatocytes showed substantial effects on cell architecture by expression of MIST1 alone, indicating that MIST1 operates largely independently of cellular context.

Mist1 is conserved in function with the Drosophila gene DIMM, which also seems both necessary and sufficient to imbue a cell with secretory architecture even in an ectopic setting (Hamanaka et al. 2010), consistent with a conserved role for this sort of functionality. As with MIST1, when DIMM was expressed ectopically by itself in non-DIMM-expressing cells, it caused wholesale cellular rearrangement into a secretory architecture (Hamanaka et al. 2010). In those experiments, when both DIMM and a secretory cargo-encoding gene were expressed, the large secretory granules that formed also were densely packed with the cargo protein. In our PC experiments, we observed abundant large secretory granules, but they were not electron-dense, possibly because MIST1 regulates only the production, size, and location of the granules but cannot affect the type or amount of cargo (e.g., VEGFB) produced, which is regulated by lineagespecific transcription factors.

We also hypothesized that a scaling factor could imbue cells with the ability to scale down their function during times of stress (Mills and Taghert 2012). During hypoxia, for example, cells might decrease MIST1 to scale back secretion and conserve resources. Work by us and others in pancreatic and gastric injury models has revealed, accordingly, that one of the first molecular features of the tissue damage response is that Mist1 expression is shut off (Nozaki et al. 2008; Lennerz et al. 2010; Huh et al. 2012; Capoccia et al. 2013; Karki et al. 2015). The downscaling caused by this loss of MIST1 may be critical, as forced expression of MIST1 during pancreatitis causes poor adaptation to injury (Karki et al. 2015).

The present study also sheds some new light on how MIST1 might work to scale secretory architecture. MIST1 is expressed in multiple long-lived secretory cells derived from every germ layer along numerous different lineage specification sequences (Schwab et al. 2000; Pin et al. 2001; Johnson et al. 2004; Capoccia et al. 2011; Metzler et al. 2015). The principal common feature among those cells is not how they differentiate but what they do: secrete large amounts of protein over a long life span. We show here that, across many different tissues, a similar cohort of genes is induced in MIST1-expressing tissues throughout the body. As that cohort seems able to cause numerous dramatic rearrangements in cellular organization, we might be able to learn some clues about how MIST1 works by studying these genes. How does a transcription factor cause such dramatic morphological changes (which are lost if MIST1 is lost) by increasing expression of certain genes?

Although functional study of each MIST1 target is beyond the scope of the present study, we can draw some conclusions, speculate, and discuss some puzzling aspects of the findings. We restricted analysis to the 23 genes that were identified in Figure 6A, focusing on those that were increased in qRT-PCR validation. As mentioned in the Results, unbiased annotation shows that nearly all (a few have not yet been extensively characterized) are membrane-associated and have functions in cytoplasmic organelles intracellularly.

Manual annotation (Supplemental Table S2) indicates that a large cohort of MIST1 targets regulates lysosomal trafficking and/or autophagic function: 5330417C22Rik, Copz2, Rab26, Wdyhv1, Ostm1, and Trabd (Lange et al. 2006; Wang et al. 2009; Behrends et al. 2010; Deng et al. 2010; Shtutman et al. 2011; Jin and Mills 2014; Pandruvada et al. 2015). We show here, and we and others have shown previously, that trafficking of lysosomes and mitochondria is regulated by MIST1 (Luo et al. 2005; Jin and Mills 2014). Autophagy control is likely critical in longlived secretory cells with high anabolic demands for producing protein; old organelles must be recycled efficiently, but there may be specific mechanisms also to preserve secretory granules from degradation until a 
signal to secrete is received. We characterized the lysosome and mitochondrial trafficking properties of RAB26 (Jin and Mills 2014) previously, and others recently have shown it to help regulate trafficking to autophagy (Binotti et al. 2015).

Not surprisingly, several MIST1 targets are involved in vesicle and membrane trafficking from ER to Golgi to secretory granules: Copz2, Ufm1, Large2, Ostm1, Ttc7b, Pon3, Tmed6, and Qpctl (Cynis et al. 2008; Lemaire et al. 2011; Schilling et al. 2011; Shtutman et al. 2011; Nakatsu et al. 2012; Schweikert et al. 2012; Wang et al. 2012; Weinert et al. 2014). COPZ2, one of the coatomer protein complex members that has not been extensively characterized, has been described previously as a MIST1 target (Direnzo et al. 2012). OSTM1 is interesting in that it seems to be a key adaptor protein involved in trafficking of lysosomes and secretory granules (e.g., melanosomes) via interaction with microtubule-associated motors (Weinert et al. 2014).

MIST1 targets are enriched in mitochondria-associated functions. This cohort comprises genes involved in mitochondrial trafficking (Rab26, Ostm1, and Pon3) and those involved in amino acid metabolism (Aass, Bckdk, Gcdh, Qtrt1, and Wdyhv1) (Hutson 2006; Cleveland et al. 2008; Wang et al. 2009; Biela et al. 2013; Seminotti et al. 2013; Hatazawa et al. 2014). The three trafficking genes seem to be involved in interactions between mitochondria and lysosomes as mentioned (Rab26 and Ostm1) and between mitochondria and the ER (Pon3). The amino acid-modifying MIST1 targets are all relatively uncharacterized "housekeeping" genes involved in amino acid interconversion and catabolism. The fact that $>20 \%$ of the core MIST1 target genes fit in this relatively uncommon gene function indicates that amino acid metabolism is a key feature of MIST1's function.

Another aspect of our analysis is the highly nonrandom distribution of E boxes in MIST1 target genes. The palindromic E-box CAATTG was conspicuously rare in the genomic sequences of mice or other aligned vertebrates within the region of MIST1 binding in the primary genomic DNA sequence of MIST1 target genes. The CAATTG E-box has not been well characterized as a binding transcription factor, with one study showing much lower affinity of USF proteins binding CAATTGs (Allen et al. 2005). It may be that evolution selects against cis genomic elements that would lead to transcription factors with possibly competing functions binding the same gene.

A recent report identified occasional cells in the isthmal stem cell zone that showed expression of an LSL reporter gene following tamoxifen activation of the Mist1-Cre $e^{E R T 2}$ allele (Hayakawa et al. 2015). Those investigators did not observe MIST1 protein in those cells, and we have never seen MIST1 protein expressed in any cell other than ZCs and their immediate precursors. Furthermore, we saw no evidence of stem-like behavior in MIST1-PCs, and none of the targets are related to an undifferentiated state or regulation of proliferation. Thus, our current results are consistent with many previous studies showing that MIST1 expression correlates with terminal differentiation and a mature secretory cell phenotype.

\section{Materials and methods}

Mouse studies

All experiments involving animals were performed according to protocols approved by the Washington University School of Med-

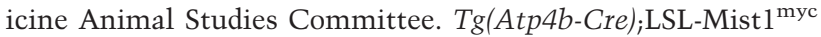
mice (referred to here as Atp $4 b-C r e ;$ LSL-Mist ${ }^{\text {myc }}$ ) were generated by crossing $\mathrm{Tg}(\mathrm{Atp} 4 \mathrm{~b}$-Cre $)$ mice with LSL-Mist $1^{\text {myc }}$ mice as described previously (Direnzo et al. 2012). Tg(Atp4b-Cre) mice (Syder et al. 2004; Huh et al. 2010) are a random insertion transgenic line expressing Cre recombinase constitutively under parietal cell-specific promoter elements of the $A t p 4 b$ gene, which encodes the $\mathrm{H}^{+}-\mathrm{K}^{+}$-ATPase acid pump $\beta$ subunit. LSL-Mist $1^{\text {myc }}$ mice have a C-terminal 6XHis-Myc-tagged rat Mist1 inducible by Cre recombinase. Lineage tracing ROSA26 $6^{\text {LSL-mTmG }}$ mice (from Jackson Laboratory) were crossed with LSL-Mist $1^{\text {myc }}$ mice to track Cre recombinase-induced recombination in gastroids and the liver.

Mist $1^{f l o x /+}$ mice were produced by generating a Mist 1 targeting vector containing loxP sites flanking the entire Mist1-coding region within exon 2 . In addition, a small biotin tag and MYC tag were added to the $\mathrm{N}$ terminus and $\mathrm{C}$ terminus, respectively, of the MIST1 ORF. Mist $1^{\text {flox/flox }}$ mice were bred to Bhlha15 ${ }^{\text {tm3(cre/ERT2)Skz }}$ mice (referred to here as Mist1 ${ }^{\text {CreERT2 }}$ ), which have a Mist1 allele replaced by a tamoxifen-activatable Cre

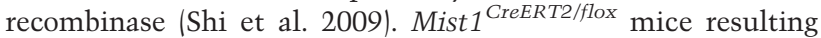
from those crosses were used to inducibly delete all Mist 1 from MIST1-expressing cells. Tamoxifen-treated littermate Mist $1^{\text {flox/flox }}$ mice served as the controls in these experiments. The Mis$t 1^{\text {CreERT2/flox }}$ and Mist $1^{\text {flox/flox }}$ mice did not have any phenotype prior to treatment with tamoxifen (Shi et al. 2009; H-YG Lo, RU Jin, and JC Mills, unpubl.).

Mice were genotyped with PCR amplification. Primer sequences for genotyping are in Supplemental Table S1.

All experiments were performed on adult mice aged 7-12 wk except for experiments as noted with aged mice that were 9-12 mo old. Mice were maintained on a mixed background. Tamoxifen (Sigma-Aldrich) was injected intraperitoneally in mice using both "high-dose" and "low-dose" protocols that have been extensively vetted previously by our laboratory and others (Huh et al. 2010, 2012; Capoccia et al. 2013; Khurana et al. 2013; Maeda et al. 2016; Saenz et al. 2016). Doses of $5 \mathrm{mg}$ per $20 \mathrm{~g}$ of mouse body weight ("high-dose") delivered on three consecutive days cause the death of $>90 \%$ of PCs within $4 \mathrm{~d}$ of the initial dose followed by recovery to a full complement of PCs by $3 \mathrm{wk}$. To study the re-emergence of PCs with forced expression of MIST1, we analyzed such recovery mice at a time of rapid recent PC regeneration: $14 \mathrm{~d}$ after initial dose. To induce Mist1 deletion in the Mist1 ${ }^{\text {CreERT2/flox mice, mice }}$ were given daily injections of "low-dose" tamoxifen (1 mg per $20 \mathrm{~g}$ of body weight) for five consecutive days.

Hepatocyte-specific MIST1 expression was accomplished by the adminstration of $5.0 \times 10^{11}$ genome copies of AAV8-TBG-iCre (Vector Laboratories) in $150 \mu \mathrm{L}$ of saline by intraperitoneal injection into 7-wk-old ROSA26 $6^{L S L-m T m G}$ mice $(n=3)$ containing the LSL-Mist $1^{\text {myc }}$ transgene and controls $(n=3)$. Mice were sacrificed $14 \mathrm{~d}$ later, and the livers were removed for subsequent analyses. Fragments of the livers were collected from all anatomic regions and processed for histology and molecular analysis independently. The experiment was repeated with two additional LSLMist $1^{\text {myc }}$ mice successfully, with equivalent results based on RT-qPCR, immunohistochemical, and histological analysis.

Immunofluorescence, immunohistochemistry, and microscopy

Stomachs were prepared and stained as described previously (Ramsey et al. 2007). The fixation and staining of livers were 
similar but with slight modifications. Livers were first diced into small cubes and subsequently fixed in $4 \%$ paraformaldehyde. Gastroid fixation and staining have been described previously (Burclaff et al. 2016). For immunohistochemistry, all steps were identical except that slides were blocked in $10 \%$ normal goat serum and $0.2 \%$ Triton X-100 in phosphate-buffered saline (PBS), and an extra quenching step was performed for $10 \mathrm{~min}$ in a methanol solution containing $1.5 \% \mathrm{H}_{2} \mathrm{O}_{2}$ following antigen retrieval.

The following primary antibodies were used: goat anti-human GIF (1:2000; gift of David Alpers, Washington University), rabbit anti-Ufm1 (1:100; Sigma-Aldrich), goat anti-VEGFB (1:100; Santa Cruz Biotechnology), mouse anti-ezrin (1:100; Santa Cruz Biotechnology), rabbit anti-myc (1:100; Cell Signaling), rabbit antiEIG121/5330417C22Rik (1:100; Prosci), mouse anti-MIST1 (1:100), sheep anti-PGII (1:10,000; Abcam), goat anti-GFP (Santa Cruz Biotechnology), and rabbit anti-cytochrome C (1:100; Abcam). Secondary antibodies used were Alexa fluor 488-, 594-, and 647-conjugated donkey anti-goat, anti-rabbit, and anti-mouse antibodies (1:500; Invitrogen) and biotinylated goat anti-rabbit secondary (Jackson Laboratory). Fluorescence microscopy was performed using a Zeiss Axiovert 200 microscope with an Axiocam MRM camera and Apotome II instrument for grid-based optical sectioning. Post-imaging adjustments, including contrast, fluorescent channel overlay, and pseudo-coloring, were with Axiovision and Adobe Photoshop CS6. For subcellular quantification of granule size, images were collected on a Zeiss LSM510 Meta microscope with a $63 \times$ (plan-apo, 1.4 NA) objective with an Axiocam MRM camera and Axiovision software.

Microscopic quantifications were with ImageJ software on optical sections. PGC secretory vesicles were traced using the circle tool and tracked using the ROI manager. After all vesicles were traced, individual areas were measured using the Analyze area measurement tool. In PCs and hepatocytes, nuclear position quantification was performed by measuring the distance from the center of the nucleus to the nearest plasma membrane. The diameter was then measured. In ZCs, the line was drawn from the nucleus to the basement membrane from H\&E images. The ratio of those measurements and the diameter of the cell produced the nuclear position normalized to cell diameter. The number of PCs per unit was manually quantified. Cell area, perimeter, and circularity were calculated by outlining individual cells from representative images and employing the measurement tool in ImageJ.

\section{Basal gastric acid pH measurement}

Mice were fasted $12 \mathrm{~h}$ prior to $\mathrm{pH}$ measurements but given free access to water. Each mouse was anesthetized with isoflurane and the gastrointestinal was tract exposed. The gastroduodenal junction was clamped with a hemostat, and $0.2 \mathrm{cc}$ of nonbuffered DNase-/RNase-free water (Sigma-Aldrich) was injected into the stomach and aspirated after 4 min with an 18-gauge 2.5-in animal feeding needle (Pet Surgical). The aspirate was centrifuged at $800 \mathrm{~g}$ for $3 \mathrm{~min}$, and $\mathrm{pH}$ was determined in triplicate with a precalibrated UB-10 (Denver Instruments) using a combination PY-P22 probe with a 5 -mm tip.

\section{Graphing and statistics}

Graphs and statistics were done with GraphPad Prism. Significance was determined using Student's $t$-test, $\chi^{2}$ test, rank-sum, or Fisher's exact test where appropriate (e.g., see "GeneChip and Bioinformatics"). Sample sizes were determined based on statistical significance and practicality. A $P$-value of $\leq 0.05$ was consid- ered significant. Samples were randomized, and measurements were blinded to prevent the introduction of experimental bias.

\section{$q R T-P C R$}

RNA was isolated using RNeasy (Qiagen) per the manufacturer's protocol. The quality of the mRNA was verified with a BioTek Take3 spectrophotometer and electrophoresis on a $2 \%$ agarose gel. RNA was treated with DNase I (Invitrogen), and $1 \mu \mathrm{g}$ of RNA was reverse-transcribed with SuperScript III (Invitrogen) following the manufacture's protocol. Measurements of cDNA abundance were performed by qRT-PCR using either a Stratagene MX3000P detection system or a Bio-Rad CFX Connect system. Power SYBR Green master mix (Thermo Scientific) fluorescence was used to quantify the relative amplicon amounts of each gene (normalizing genes were $18 \mathrm{~S}$ or $\beta$-Actin). Primer design and sequence are in Supplemental Table S1.

\section{FIB-SEM 3D nanotomography}

Mouse gastric tissues were bisected into fixative containing $2.5 \%$ glutaraldehyde and $2 \%$ paraformaldehyde in $0.15 \mathrm{M}$ cacodylate buffer containing $2 \mathrm{mM} \mathrm{CaCl}_{2}$ (pH 7.4), fixed for $15 \mathrm{~min}$ at $37^{\circ} \mathrm{C}$ and then overnight at $4^{\circ} \mathrm{C}$, sliced into $\sim 1.5$-mm-thick pieces, rinsed in cacodylate buffer for $10 \mathrm{~min}$ at room temperature, and subjected to secondary fixation in $1 \%$ osmium tetroxide $/ 0.3 \%$ potassium ferrocyanide in cacodylate buffer for $1 \mathrm{~h}$ on ice. The samples were then washed in ultrapure water and stained en bloc in $2 \%$ aqueous uranyl acetate for $1 \mathrm{~h}$. After staining, samples were briefly washed in ultrapure water, dehydrated in a graded acetone series, and infiltrated with microwave assistance (Pelco BioWave Pro) into LX112 resin, which was cured in an oven for $48 \mathrm{~h}$ at $60^{\circ} \mathrm{C}$. Cured blocks were trimmed and mounted onto SEM pins with silver epoxy and faced with a diamond knife. Toluidine blue-stained sections (300 $\mathrm{nm}$ thick) were used to locate a region of interest. Blocks were sputter-coated with $10 \mathrm{~nm}$ of iridium (Leica, ACE $600)$ with rotation on a planetary stage to ensure saturation. Regions of interest on a FIB-SEM (Zeiss, Crossbeam 540) were located by secondary electron imaging at $10 \mathrm{KeV}$. Once a region was found, the sample was prepared using the ATLAS (Fibics) 3D nanotomography engine. In short, a platinum pad was deposited on a $40-\mu \mathrm{m} \times 40-\mu \mathrm{m}$ region of interest with the FIB set to $30 \mathrm{KeV}$ and $1.5 \mathrm{nA}$. Three vertical lines for focus and sigmation and two angled lines for z-tracking were milled into the platinum pad at $50 \mathrm{pA}$, and a protective pad of carbon was deposited on top of the milled platinum at $1.5 \mathrm{nA}$. Following this, a rough trench $50 \mu \mathrm{m}$ wide and $55 \mu \mathrm{m}$ deep was milled at $30 \mathrm{nA}$ and polished at $7 \mathrm{nA}$. Once polishing of the block face was complete, face detection, focusing, and ztracking were all performed on the fiducial marks that were milled into the platinum pad. Imaging was performed at $2 \mathrm{KeV}$ and $1.1 \mathrm{nA}$ using the EsB (energy selective backscatter) detector with a grid voltage of $1100 \mathrm{~V}$. The block was milled at a current of $700 \mathrm{pA}$ with 20 -nm slices, and $2000 \times 1750$ pixel images were acquired at a resolution of $20 \mathrm{~nm} /$ pixel with a dwell of 8 or $10 \mu \mathrm{sec}$ and a line average of 3 for a total z-depth of $35 \mu \mathrm{m}$.

\section{$3 D$ reconstruction}

All EM serial images were imported into the Amira 63D software package for $3 \mathrm{D}$ reconstruction. Areas of interest were manually segmented into data objects with intervening unsegmented slices $\left(\right.$ " $\left.\mathrm{X}^{\prime \prime}\right)$ based on object volume. For organelles with suboptimal contrast, the thresholding function was used for manual segmentation. The interpolation function was used to highlight areas of interest between manually segmented slices. 3D models were 
generated from labeled objects. The "Smooth" and "Simplify" functions were used for model generation, and pseudocoloring was used to enhance visualization for each organelle. Animations were created with the Animation Director in the software. Volume measurements were performed as per the Amira6 3D software instructions. Measurements $<1 \times 10^{5} \mathrm{~m}$ were excluded due to a lack of resolution in the Z-stack.

$E M$

For TEM, stomachs were fixed, sectioned, stained, and imaged as described previously (Capoccia et al. 2013).

\section{GeneChip and bioinformatics}

A $0.5-\mathrm{cm}^{2}$ section of corpus stomach was collected from Atp $4 b^{\text {Cre }}$;LSL-Mist $1^{\text {myc }}$ transgenic and control mice, and RNA was purified using RNeasy (Qiagen). RNA integrity was analyzed via Agilent Bioanalyzer, and samples were processed and hybridized to Affymetrix Mouse Gene 2.0 ST expression arrays per the manufacturer's instructions as performed by the Washington University Genome Technology Access Core (GTAC). GeneChips were analyzed with Partek analysis (record GSE81549) (Direnzo et al. 2012). To determine the overlap between genes increased by MIST1 forced expression in PCs and MIST1-induced genes in pancreatic acinar cells, we first identified the cohort of 250 genes increased with $P<0.001$ (after Bonferroni multiple hypothesis correction) in both wild-type versus Mist $1^{-/}$acinar cells and Mist 1 rescue versus Mist $1^{-1-}$ acinar cells. We then determined the minimal fold change threshold for the gastric MIST1-PC versus control GeneChips that resulted in a $\chi^{2} P$-value of $<0.001$ for significant overlap between the acinar and PC profiles, yielding the 36 genes shown in Supplemental Figure S6A. We also analyzed GeneChip data from laser-captured wild-type versus Mist $1^{-/-}$ZCs and neck cells (record GSE 43441) (Capoccia et al. 2013). Genes were categorized as "dependent" on MIST1 expression in chief cells if they were above the level of detection and fulfilled the following criteria: (1) exhibited significantly increased expression in wild-type ZCs compared with wild-type neck cells, (2) showed decreased expression in the ZCs of Mist $1^{-/-}$ZCs versus wild type, and (3) did not have increased expression in the neck cells of Mist $1^{-1-}$ neck cells versus Mist $1^{-/-}$ ZCs. Two transcripts, Pon3 and Paip2b, met the first two more important criteria but showed low-level neck cell expression in both null and wild-type mice.

In another analysis, we used a database of organ-specific gene expression provided by GeneVisible (Hruz et al. 2008) to determine the 10 organs in which MIST1 and each potential MIST1 target gene were most preferentially expressed. The number of "top 10" tissues shared between MIST1 and each putative target was determined as an assessment of correlation with MIST1 tissue-specific expression patterns. The 10 tissues in which MIST1 was most enriched were extraembryonic tissue/fluid, lacrimal gland, pancreas, Paneth cell, parotid gland, pituitary gland (hypophysis), placenta, prostate (prostate gland), salivary gland, and seminal vesicle. These tissue correlation patterns were highly statistically significant. At the time of analysis, there were 302 separate tissues in the database. Of the 10 tissues in which MIST1 was most commonly expressed, five were also among the top 10 tissues for expression of three putative MIST1 target genes (5330417C22Rik, Large2, and Qpct1). Three more targets (Copz2, Nudt22, and Bckdk) had four overlapping genes in their top 10. We set the cutoff for significance at a three-tissue overlap, since, if all tissue profiles could be treated with equal weight, the odds of there being three genes at random overlapping between two top 10 lists from a 302-member pool would be approximately $P<0.01$. In reality, our analysis is likely too stringent, as we did a control analysis using genes that showed no fold change difference in MIST1-PCs versus controls to determine the pattern of tissue overlap of these randomly chosen genes. Of 12 random genes (the same number that showed a more than three-tissue overlap among our putative targets) only one shared even a single tissue among its top 10 most expressed with MIST1's top 10 most expressed $(P<0.003)$.

Raymond MacDonald from the University of Texas Southwestern (pers. comm.; part of this work recently published in Jiang et al. 2016) generously provided us with acinar ChIP-seq data from chromatin immunoprecipitated from pancreatic acinar cells using a rabbit anti-MIST1 antibody that we generated previously (Lennerz et al. 2010). The raw data were processed using Partek software to determine significant MIST1-binding peaks ( $P$-value $<0.05$ ) and the distances of the peaks from the TSS of each gene. The subset of significant peaks in our cohort of putative MIST1 targets was used for subsequent analyses. Using the MEME suite (Bailey and Elkan 1994), we derived the most common motif within $1000 \mathrm{bp}$ of the ChIP-seq peaks $(P$-value $<0.01)$ of our putative MIST1 targets that had significant MIST1-bound peaks. To determine evolutionary conservation of $\mathrm{E}$ boxes, the MultizAlign tool in the University of California at Santa Cruz genome browser was used (including species from rats to opossums). Each E box (CANNTG) near ChIP-seq peaks within the first intron was determined using the Short Match tool, and sequence conservation was determined manually across species.

To count the frequency of E-box motifs within a larger set of MIST1 target genes, DNA sequences were obtained from mouse reference genome (assembly $\mathrm{mm} 10$ ) by using Bedtools. The gene promoters were defined as a $2-\mathrm{kb}$ sequence around the gene TSS of the 214 genes whose expression was dependent on MIST1 and also contained MIST1-bound peaks on ChIP-seq within their promoters. Sixteen combinations of CANNTG were counted in both positive sense and negative sense of a 2-kb DNA sequence, and their locations were recorded by using an in-house script. For one set of control sequences neighboring the ChIP-seq peak, the 16 combinations of CANNTG were counted in both a positivesense and a negative-sense DNA sequence $1 \mathrm{~kb}$ upstream of/ downstream from the ChIP-seq peak. The enrichment scores in the third column of Figure 6C were calculated by the frequency of a given CANNTG sequence within the MIST1 ChIP-seq peak relative to its frequency within the flanking $1-\mathrm{kb}$ regions (with each prevalence normalized relative to the length of DNA, given that ChIP-seq peaks were not all of exactly equal length). The E-box frequencies within other control sequences were also run, such as within promoters of genes not bound by MIST1 and not showing a statistically significant MIST1-dependent change in transcript expression. In general, control sequences were indistinguishable from the flanking DNA control, so we used only the flanking sequence controls for the final analysis in Figure 6C.

Finally, mRNA was purified and analyzed from $L S L-M i s t 1^{\text {myc }}$ transgenic mice injected with AAV8-TBG-iCre using the same methods as described previously. Samples were processed and hybridized to Affymetrix Mouse Gene 2.0 ST microarrays. All genes that were above the statistically significant threshold derived from the stomach GeneChips were determined "up-regulated" in our analyses (record GSE93612).

\section{Acknowledgments}

We thank Ray MacDonald and Chinh Hoang from the Department of Molecular Biology, University of Texas Southwestern 
Medical Center, for the experimental pancreatic acinar ChIP-seq data set and for reviewing the manuscript. We are grateful for support from the Washington University Center for Cellular Imaging, which is funded by the Washington University School of Medicine, the Children's Discovery Institute of Washington University, and St. Louis Children's Hospital (CDI-CORE-2015-505); the Foundation for Barnes-Jewish Hospital (3770); the National Institute for Neurological Disorders and Stroke (NS086741); the Washington University Center for Regenerative Medicine; and the Washington University Digestive Disease Core Center (DDRCC) Advanced Imaging and Tissue Analysis Core (AITAC; funded by P30 DK052574). J.C.M. is funded by the National Institutes of Health (NIH) National Institute of Diabetes and Digestive and Kidney Diseases (R01 DK094989 and R01 DK105129); S.F.K. is funded by NIH DK55489 and CA124586; N.O.D. is funded by HL38180, DK112378, and DK56260; B.B.M. is funded by NIH DK093885 and DK108764; and B.Z. is funded by NIH DA027995. J.C.M., B.B.M., and N.O.D. are all funded by the Siteman Cancer Center Investment Program and DK052574. H.-Y.G. L., R.U.J., G.S., D.L., A.K., M.S.J., and V.B. performed experiments; H.-Y.G.L. and J.C.M. wrote the manuscript; G.S. originated the study; B.B.M. designed experiments and provided key reagents; B.Z. performed bioinformatics and statistics; J.A.J.F. designed the experiments; N.O.D. provided key reagents, conceived the experiments, and edited the manuscript; S.F.K. provided unique reagents; and J.C.M. performed bioinformatic studies and funded the project.

\section{References}

Allen RR, Qi L, Higgins PJ. 2005. Upstream stimulatory factor regulates E box-dependent PAI-1 transcription in human epidermal keratinocytes. J Cell Physiol 203: 156-165.

Bailey TL, Elkan C. 1994. Fitting a mixture model by expectation maximization to discover motifs in biopolymers. Proc Int Conf Intell Syst Mol Biol 2: 28-36.

Behrends C, Sowa ME, Gygi SP, Harper JW. 2010. Network organization of the human autophagy system. Nature 466: 68-76.

Biela I, Tidten-Luksch N, Immekus F, Glinca S, Nguyen TX, Gerber HD, Heine A, Klebe G, Reuter K. 2013. Investigation of specificity determinants in bacterial tRNA-guanine transglycosylase reveals queuine, the substrate of its eucaryotic counterpart, as inhibitor. PLoS One 8: e64240.

Binotti B, Pavlos NJ, Riedel D, Wenzel D, Vorbruggen G, Schalk AM, Kuhnel K, Boyken J, Erck C, Martens H, et al. 2015. The GTPase Rab26 links synaptic vesicles to the autophagy pathway. Elife 4: e05597.

Bredemeyer AJ, Geahlen JH, Weis VG, Huh WJ, Zinselmeyer BH, Srivatsan S, Miller MJ, Shaw AS, Mills JC. 2009. The gastric epithelial progenitor cell niche and differentiation of the zymogenic (chief) cell lineage. Dev Biol 325: 211-224.

Burclaff J, Osaki LH, Liu D, Goldenring JR, Mills JC. 2016. Targeted apoptosis of parietal cells is insufficient to induce metaplasia in stomach. Gastroenterology doi: 10.1053/j.gastro.2016. 12.001 .

Capoccia BJ, Huh WJ, Mills JC. 2009. How form follows functional genomics: gene expression profiling gastric epithelial cells with a particular discourse on the parietal cell. Physiol Genomics 37: 67-78.

Capoccia BJ, Lennerz JK, Bredemeyer AJ, Klco JM, Frater JL, Mills JC. 2011. Transcription factor MIST1 in terminal differentiation of mouse and human plasma cells. Physiol Genomics 43: $174-186$.
Capoccia BJ, Jin RU, Kong YY, Peek RM Jr, Fassan M, Rugge M, Mills JC. 2013. The ubiquitin ligase Mindbomb 1 coordinates gastrointestinal secretory cell maturation. J Clin Invest 123: 1475-1491.

Chikada H, Ito K, Yanagida A, Nakauchi H, Kamiya A. 2015. The basic helix-loop-helix transcription factor, Mist1, induces maturation of mouse fetal hepatoblasts. Sci Rep 5: 14989.

Cleveland BM, Kiess AS, Blemings KP. 2008. a-Aminoadipate $\delta$-semialdehyde synthase mRNA knockdown reduces the lysine requirement of a mouse hepatic cell line. I Nutr 138: 2143-2147.

Cynis H, Rahfeld JU, Stephan A, Kehlen A, Koch B, Wermann M, Demuth HU, Schilling S. 2008. Isolation of an isoenzyme of human glutaminyl cyclase: retention in the Golgi complex suggests involvement in the protein maturation machinery. J Mol Biol 379: 966-980.

D'Amour KA, Bang AG, Eliazer S, Kelly OG, Agulnick AD, Smart NG, Moorman MA, Kroon E, Carpenter MK, Baetge EE. 2006. Production of pancreatic hormone-expressing endocrine cells from human embryonic stem cells. Nat Biotechnol 24: 1392-1401.

Degnan BM, Vervoort M, Larroux C, Richards GS. 2009. Early evolution of metazoan transcription factors. Curr Opin Genet Dev 19: 591-599.

Deng L, Feng J, Broaddus RR. 2010. The novel estrogen-induced gene EIG121 regulates autophagy and promotes cell survival under stress. Cell Death Dis 1: e32.

Direnzo D, Hess DA, Damsz B, Hallett JE, Marshall B, Goswami C, Liu Y, Deering T, Macdonald RJ, Konieczny SF. 2012. Induced Mist1 expression promotes remodeling of mouse pancreatic acinar cells. Gastroenterology 143: 469-480.

Edlund T, Jessell TM. 1999. Progression from extrinsic to intrinsic signaling in cell fate specification: a view from the nervous system. Cell 96: 211-224.

Forte TM, Machen TE, Forte JG. 1977. Ultrastructural changes in oxyntic cells associated with secretory function: a membranerecycling hypothesis. Gastroenterology 73: 941-955.

Garside VC, Kowalik AS, Johnson CL, DiRenzo D, Konieczny SF, Pin CL. 2010. MIST1 regulates the pancreatic acinar cell expression of Atp2c2, the gene encoding secretory pathway calcium ATPase 2. Exp Cell Res 316: 2859-2870.

Hadzic T, Park D, Abruzzi KC, Yang L, Trigg JS, Rohs R, Rosbash M, Taghert PH. 2015. Genome-wide features of neuroendocrine regulation in Drosophila by the basic helix-loop-helix transcription factor DIMMED. Nucleic Acids Res 43: 2199-2215.

Hamanaka Y, Park D, Yin P, Annangudi SP, Edwards TN, Sweedler J, Meinertzhagen IA, Taghert PH. 2010. Transcriptional orchestration of the regulated secretory pathway in neurons by the bHLH protein DIMM. Curr Biol 20: 9-18.

Hanzel D, Reggio H, Bretscher A, Forte JG, Mangeat P. 1991. The secretion-stimulated $80 \mathrm{~K}$ phosphoprotein of parietal cells is ezrin, and has properties of a membrane cytoskeletal linker in the induced apical microvilli. EMBO J 10: 2363-2373.

Hatazawa Y, Tadaishi M, Nagaike Y, Morita A, Ogawa Y, Ezaki O, Takai-Igarashi T, Kitaura Y, Shimomura Y, Kamei Y, et al. 2014. PGC-1 $\alpha$-mediated branched-chain amino acid metabolism in the skeletal muscle. PLoS One 9: e91006.

Hayakawa Y, Ariyama H, Stancikova J, Sakitani K, Asfaha S, Renz BW, Dubeykovskaya ZA, Shibata W, Wang H, Westphalen CB, et al. 2015. Mist1 expressing gastric stem cells maintain the normal and neoplastic gastric epithelium and are supported by a perivascular stem cell niche. Cancer Cell 28: 800-814.

Hruz T, Laule O, Szabo G, Wessendorp F, Bleuler S, Oertle L, Widmayer P, Gruissem W, Zimmermann P. 2008. Genevestigator 
v3: a reference expression database for the meta-analysis of transcriptomes. Adv Bioinformatics 2008: 420747.

Hu BY, Weick JP, Yu J, Ma LX, Zhang XQ, Thomson JA, Zhang SC. 2010. Neural differentiation of human induced pluripotent stem cells follows developmental principles but with variable potency. Proc Natl Acad Sci 107: 4335-4340.

Hu X, Pang Q, Shen Q, Liu H, He J, Wang J, Xiong J, Zhang H, Chen F. 2014. Ubiquitin-fold modifier 1 inhibits apoptosis by suppressing the endoplasmic reticulum stress response in Raw264.7 cells. Int J Mol Med 33: 1539-1546.

Huang DE, Sherman BT, Lempicki RA. 2009a. Bioinformatics enrichment tools: paths toward the comprehensive functional analysis of large gene lists. Nucleic Acids Res 37: 1-13.

Huang DW, Sherman BT, Lempicki RA. 2009b. Systematic and integrative analysis of large gene lists using DAVID bioinformatics resources. Nat Protoc 4: 44-57.

Huh WJ, Esen E, Geahlen JH, Bredemeyer AJ, Lee AH, Shi G, Konieczny SF, Glimcher LH, Mills JC. 2010. XBP1 controls maturation of gastric zymogenic cells by induction of MIST1 and expansion of the rough endoplasmic reticulum. Gastroenterology 139: 2038-2049.

Huh WJ, Khurana SS, Geahlen JH, Kohli K, Waller RA, Mills JC. 2012. Tamoxifen induces rapid, reversible atrophy, and metaplasia in mouse stomach. Gastroenterology 142: 21-24 e27.

Hutson SM. 2006. The case for regulating indispensable amino acid metabolism: the branched-chain $\alpha$-keto acid dehydrogenase kinase-knockout mouse. Biochem J 400: e1-e3.

Ieda M, Fu JD, Delgado-Olguin P, Vedantham V, Hayashi Y, Bruneau BG, Srivastava D. 2010. Direct reprogramming of fibroblasts into functional cardiomyocytes by defined factors. Cell 142: 375-386.

Jiang M, Azevedo-Pouly A, Deering TG, Hoang CQ, DiRenzo D, Hess DA, Konieczny SF, Swift GH, MacDonald RJ. 2016. MIST1 and PTF1 collaborate in feed-forward regulatory loops that maintain the pancreatic acinar phenotype in adult mice. Mol Cell Biol doi: 10.1128/MCB.00370-16.

Jin RU, Mills JC. 2014. RAB26 coordinates lysosome traffic and mitochondrial localization. J Cell Sci 127: 1018-1032.

Johnson CL, Kowalik AS, Rajakumar N, Pin CL. 2004. Mist1 is necessary for the establishment of granule organization in serous exocrine cells of the gastrointestinal tract. Mech Dev 121: 261-272.

Karam SM. 1993. Dynamics of epithelial cells in the corpus of the mouse stomach. IV. Bidirectional migration of parietal cells ending in their gradual degeneration and loss. Anat Rec 236: 314-332.

Karam SM, Leblond CP. 1993. Dynamics of epithelial cells in the corpus of the mouse stomach. III. Inward migration of neck cells followed by progressive transformation into zymogenic cells. Anat Rec 236: 297-313.

Karki A, Humphrey SE, Steele RE, Hess DA, Taparowsky EJ, Konieczny SF. 2015. Silencing Mist1 gene expression is essential for recovery from acute pancreatitis. PLoS One 10: e0145724.

Khurana SS, Riehl TE, Moore BD, Fassan M, Rugge M, RomeroGallo J, Noto J, Peek RM Jr, Stenson WF, Mills JC. 2013. The hyaluronic acid receptor CD44 coordinates normal and metaplastic gastric epithelial progenitor cell proliferation. I Biol Chem 288: 16085-16097.

Lange PF, Wartosch L, Jentsch TJ, Fuhrmann JC. 2006. ClC-7 requires Ostm 1 as a $\beta$-subunit to support bone resorption and lysosomal function. Nature 440: 220-223.

Lemaire K, Moura RF, Granvik M, Igoillo-Esteve M, Hohmeier HE, Hendrickx N, Newgard CB, Waelkens E, Cnop M, Schuit F. 2011. Ubiquitin fold modifier 1 (UFM1) and its target UFBP1 protect pancreatic $\beta$ cells from ER stress-induced apoptosis. PLoS One 6: e18517.

Lennerz JK, Kim SH, Oates EL, Huh WJ, Doherty JM, Tian X, Bredemeyer AJ, Goldenring JR, Lauwers GY, Shin YK, et al. 2010. The transcription factor MIST1 is a novel human gastric chief cell marker whose expression is lost in metaplasia, dysplasia, and carcinoma. Am J Pathol 177: 1514-1533.

Luo X, Shin DM, Wang X, Konieczny SF, Muallem S. 2005. Aberrant localization of intracellular organelles, $\mathrm{Ca}^{2+}$ signaling, and exocytosis in Mistl null mice. I Biol Chem 280: 12668-12675.

Maeda Y, Echizen K, Oshima H, Yu L, Sakulsak N, Hirose O, Yamada Y, Taniguchi T, Jenkins BJ, Saya H, et al. 2016. Myeloid differentiation factor 88 signaling in bone marrow-derived cells promotes gastric tumorigenesis by generation of inflammatory microenvironment. Cancer Prev Res (Phila) 9: 253-263.

Metzler MA, Venkatesh SG, Lakshmanan J, Carenbauer AL, Perez SM, Andres SA, Appana S, Brock GN, Wittliff JL, Darling DS. 2015. A systems biology approach identifies a regulatory network in parotid acinar cell terminal differentiation. PLoS One 10: e0125153.

Mills JC, Shivdasani RA. 2011. Gastric epithelial stem cells. Gastroenterology 140: 412-424.

Mills JC, Taghert PH. 2012. Scaling factors: transcription factors regulating subcellular domains. Bioessays 34: 10-16.

Morris SA, Cahan P, Li H, Zhao AM, San Roman AK, Shivdasani RA, Collins JJ, Daley GQ. 2014. Dissecting engineered cell types and enhancing cell fate conversion via CellNet. Cell 158: 889-902.

Nakatsu F, Baskin JM, Chung J, Tanner LB, Shui G, Lee SY, Pirruccello $M$, Hao $M$, Ingolia NT, Wenk MR, et al. 2012. PtdIns4P synthesis by PI4KIIIa at the plasma membrane and its impact on plasma membrane identity. I Cell Biol 199: 1003-1016.

Nozaki K, Ogawa M, Williams JA, Lafleur BJ, Ng V, Drapkin RI, Mills JC, Konieczny SF, Nomura S, Goldenring JR. 2008. A molecular signature of gastric metaplasia arising in response to acute parietal cell loss. Gastroenterology 134: 511-522.

Pandruvada SN, Beauregard J, Benjannet S, Pata M, Lazure C, Seidah NG, Vacher J. 2015. Role of Ostm1 cytosolic complex with kinesin 5B in intracellular dispersion and trafficking. Mol Cell Biol 36: 507-521.

Park D, Shafer OT, Shepherd SP, Suh H, Trigg JS, Taghert PH. 2008. The Drosophila basic helix-loop-helix protein DIMMED directly activates PHM, a gene encoding a neuropeptide-amidating enzyme. Mol Cell Biol 28: 410-421.

Park D, Hadzic T, Yin P, Rusch J, Abruzzi K, Rosbash M, Skeath JB, Panda S, Sweedler JV, Taghert PH. 2011. Molecular organization of Drosophila neuroendocrine cells by Dimmed. Curr Biol 21: 1515-1524.

Pin CL, Bonvissuto AC, Konieczny SF. 2000. Mist1 expression is a common link among serous exocrine cells exhibiting regulated exocytosis. Anat Rec 259: 157-167.

Pin CL, Rukstalis JM, Johnson C, Konieczny SF. 2001. The bHLH transcription factor Mist1 is required to maintain exocrine pancreas cell organization and acinar cell identity. I Cell Biol 155: 519-530.

Ramsey VG, Doherty JM, Chen CC, Stappenbeck TS, Konieczny SF, Mills JC. 2007. The maturation of mucus-secreting gastric epithelial progenitors into digestive-enzyme secreting zymogenic cells requires Mist1. Development 134: 211-222.

Saenz JB, Burclaff J, Mills JC. 2016. Modeling murine gastric metaplasia through tamoxifen-induced acute parietal cell loss. Methods Mol Biol 1422: 329-339. 
Schilling S, Kohlmann S, Bauscher C, Sedlmeier R, Koch B, Eichentopf R, Becker A, Cynis H, Hoffmann T, Berg S, et al. 2011. Glutaminyl cyclase knock-out mice exhibit slight hypothyroidism but no hypogonadism: implications for enzyme function and drug development. I Biol Chem 286: 14199-14208.

Schubert ML. 2009. Gastric exocrine and endocrine secretion. Curr Opin Gastroenterol 25: 529-536.

Schwab MH, Bartholomae A, Heimrich B, Feldmeyer D, DruffelAugustin S, Goebbels S, Naya FJ, Zhao S, Frotscher M, Tsai MJ, et al. 2000. Neuronal basic helix-loop-helix proteins (NEX and $\beta 2 /$ Neuro D) regulate terminal granule cell differentiation in the hippocampus. J Neurosci 20: 3714-3724.

Schweikert EM, Devarajan A, Witte I, Wilgenbus P, Amort J, Forstermann U, Shabazian A, Grijalva V, Shih DM, Farias-Eisner $\mathrm{R}$, et al. 2012. PON3 is upregulated in cancer tissues and protects against mitochondrial superoxide-mediated cell death. Cell Death Differ 19: 1549-1560.

Seminotti B, Amaral AU, da Rosa MS, Fernandes CG, Leipnitz G, Olivera-Bravo S, Barbeito L, Ribeiro CA, de Souza DO, Woontner M, et al. 2013. Disruption of brain redox homeostasis in glutaryl-CoA dehydrogenase deficient mice treated with high dietary lysine supplementation. Mol Genet Metab 108: 30-39.

Shao JS, Schepp W, Alpers DH. 1998. Expression of intrinsic factor and pepsinogen in the rat stomach identifies a subset of parietal cells. Am I Physiol 274: G62-G70.

Shi G, Zhu L, Sun Y, Bettencourt R, Damsz B, Hruban RH, Konieczny SF. 2009. Loss of the acinar-restricted transcription factor Mist1 accelerates Kras-induced pancreatic intraepithelial neoplasia. Gastroenterology 136: 1368-1378.

Shtutman M, Baig M, Levina E, Hurteau G, Lim CU, Broude E, Nikiforov M, Harkins TT, Carmack CS, Ding Y, et al. 2011. Tumor-specific silencing of COPZ2 gene encoding coatomer protein complex subunit $\zeta 2$ renders tumor cells dependent on its paralogous gene COPZ1. Proc Natl Acad Sci 108: 12449-12454.

Spence JR, Mayhew CN, Rankin SA, Kuhar MF, Vallance JE, Tolle K, Hoskins EE, Kalinichenko VV, Wells SI, Zorn AM, et al.
2011. Directed differentiation of human pluripotent stem cells into intestinal tissue in vitro. Nature 470: 105-109.

Syder AJ, Karam SM, Mills JC, Ippolito JE, Ansari HR, Farook V, Gordon JI. 2004. A transgenic mouse model of metastatic carcinoma involving transdifferentiation of a gastric epithelial lineage progenitor to a neuroendocrine phenotype. Proc Natl Acad Sci 101: 4471-4476.

Takayama K, Inamura M, Kawabata K, Katayama K, Higuchi M, Tashiro K, Nonaka A, Sakurai F, Hayakawa T, Furue MK, et al. 2012. Efficient generation of functional hepatocytes from human embryonic stem cells and induced pluripotent stem cells by HNF4a transduction. Mol Ther 20: 127-137.

Tian X, Jin RU, Bredemeyer AJ, Oates EJ, Blazewska KM, McKenna CE, Mills JC. 2010. RAB26 and RAB3D are direct transcriptional targets of MIST1 that regulate exocrine granule maturation. Mol Cell Biol 30: 1269-1284.

Wang H, Piatkov KI, Brower CS, Varshavsky A. 2009. Glutaminespecific $\mathrm{N}$-terminal amidase, a component of the $\mathrm{N}$-end rule pathway. Mol Cell 34: 686-695.

Wang X, Yang R, Jadhao SB, Yu D, Hu H, Glynn-Cunningham N, Sztalryd C, Silver KD, Gong DW. 2012. Transmembrane emp24 protein transport domain 6 is selectively expressed in pancreatic islets and implicated in insulin secretion and diabetes. Pancreas 41: 10-14.

Weinert S, Jabs S, Hohensee S, Chan WL, Kornak U, Jentsch TJ. 2014. Transport activity and presence of ClC-7/Ostm 1 complex account for different cellular functions. EMBO Rep 15: 784-791.

Willet SG, Mills JC. 2016. Stomach organ and cell lineage differentiation: from embryogenesis to adult homeostasis. Cell Mol Gastroenterol Hepatol 2: 546-559.

Zhao Y, Johansson C, Tran T, Bettencourt R, Itahana Y, Desprez PY, Konieczny SF. 2006. Identification of a basic helix-loophelix transcription factor expressed in mammary gland alveolar cells and required for maintenance of the differentiated state. Mol Endocrinol 20: 2187-2198.

Zhu L, Crothers J Jr, Zhou R, Forte JG. 2010. A possible mechanism for ezrin to establish epithelial cell polarity. Am J Physiol Cell Physiol 299: C431-C443. 


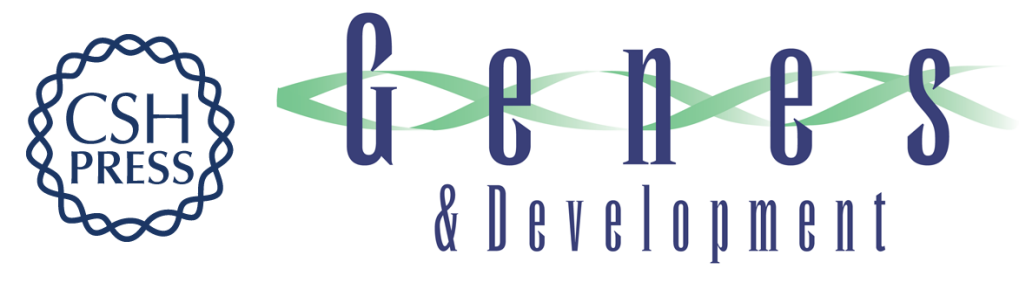

\section{A single transcription factor is sufficient to induce and maintain secretory cell architecture}

Hei-Yong G. Lo, Ramon U. Jin, Greg Sibbel, et al.

Genes Dev. 2017, 31: originally published online February 7, 2017

Access the most recent version at doi:10.1101/gad.285684.116

\section{Supplemental http://genesdev.cshlp.org/content/suppl/2017/02/07/gad.285684.116.DC1 Material}

References This article cites 77 articles, 18 of which can be accessed free at: http://genesdev.cshlp.org/content/31/2/154.full.html\#ref-list-1

Creative This article is distributed exclusively by Cold Spring Harbor Laboratory Press for the first Commons six months after the full-issue publication date (see

License http://genesdev.cshlp.org/site/misc/terms.xhtml). After six months, it is available under a Creative Commons License (Attribution-NonCommercial 4.0 International), as described at http://creativecommons.org/licenses/by-nc/4.0/.

Email Alerting Receive free email alerts when new articles cite this article - sign up in the box at the top Service right corner of the article or click here.

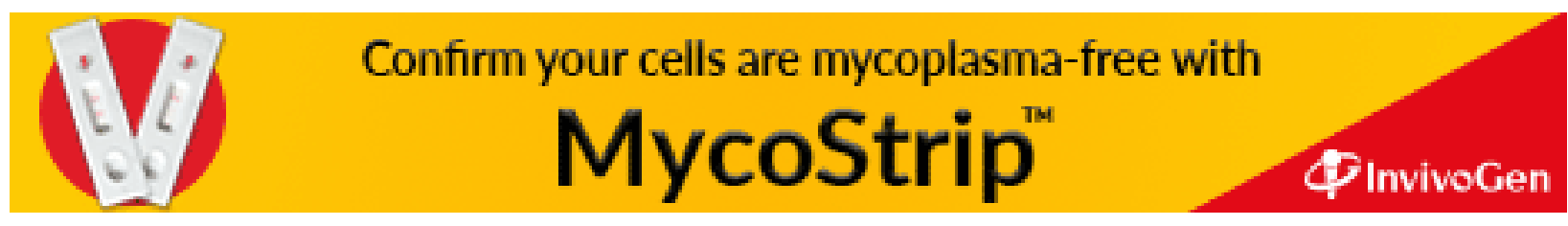

